University of Rhode Island

DigitalCommons@URI

Open Access Master's Theses

1986

\title{
Utilization of Dietary Carbohydrates and Lipids by Salmonids Sexually Sterilized with 17alpha-Methyltestosterone
}

Bruce S. Ahern

University of Rhode Island

Follow this and additional works at: https://digitalcommons.uri.edu/theses

\section{Recommended Citation}

Ahern, Bruce S., "Utilization of Dietary Carbohydrates and Lipids by Salmonids Sexually Sterilized with 17alpha-Methyltestosterone" (1986). Open Access Master's Theses. Paper 938.

https://digitalcommons.uri.edu/theses/938

This Thesis is brought to you for free and open access by DigitalCommons@URI. It has been accepted for inclusion in Open Access Master's Theses by an authorized administrator of DigitalCommons@URI. For more information, please contact digitalcommons@etal.uri.edu. 


\section{UTILIZATION OF DIETARY CARBOHYDRATES}

\section{AND LIPIDS BY SALMONIDS}

SEXUALLY STERILIZED WITH 17 IIPha-METHYLTESTOSTERONE BY

BRLCE $\Im$. AHERN

A THESIS SUBMITTED IN FAFTTIAL FULLFILLMENT OF THE FEQUIREMENTS FDF THE DEGFEE DF MASTEF: OF SCIENCE

IN

FISHEFIES AQUACULTUFE AND PATHOLDGY

LNIVERSITY OF FHODE ISLAND

1986 


\section{MASTER OF SCIENCE THESIS}

OF

BRUCE S. AHERN

Approved:

Thes is Committee

Major Professor

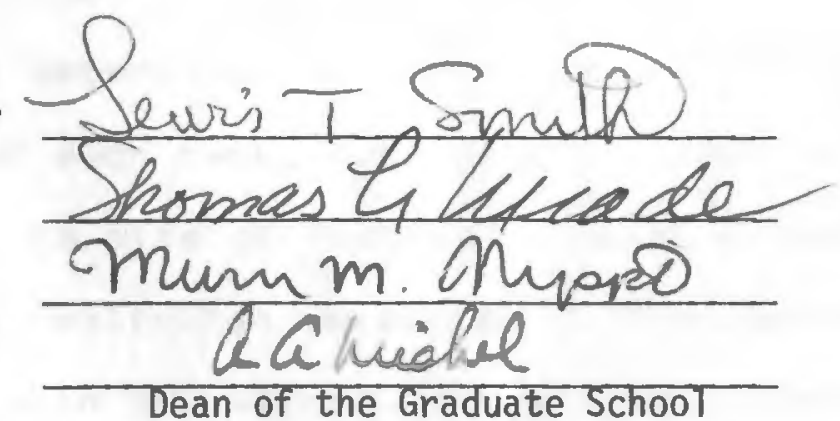

UNIVERSITY OF RHODE ISLAND

1986 


\section{ABSTRACT}

Two, twelve weet feeding trials were conducted to determine the performance of juvenile and yearling rainbow trout (salmo gairdreri) which were fed high-fat or high-carbohydrate diets. In each feeding trial and for each diet group, So\% of the fish used had been previously treated with 17 a-methly-testosterone, given orally at the onset of feeding. These were called treated fist. Also, for each group, $50 \%$ were untreated rainbow trout (controls), kept and fed under identical conditions as treated fish. All fish were held in $100 \%$ flow-through systems and fed twice or three times daily. Feed requimement was determined as a percentage of the total fish weight for each tank, according to water temper"ature. and average size of fish calculated at each growth theck. Three replicates were used in the first feeding trial and two in the second. Growth measurements: were mide every three weeks. Performance was determined through feed conversion efficiency, actual weight gain, actulal length gain, relative weight gain and condition factor. Flasme glucose and ammonia levels, and visceral fat levels wore measured to obtain an estimation of the Effects of diet and treatment on these parameters.

Two diets were formulated in the first trial, one high in 1 ipid $(24.1 \%$ ) with no carbohydrate added and the other 
lower in lipid (15\%) and high in sucrose (23.8\%) as a digestible cambohydrate. In the second trial three diets were formulated: one high in fat (24.1\% 1 ipid), one high in sucrose $(25.8 \%)$ and $10 w$ in lipid $(14.1 \%)$, and one high in molasses $(42.0 \%$ ) and low in lipid. All diets were iso-nitrogenous ard iso-caloric. The objective in these studies was to determire if a correlation existed between performance of treated or control rainbow trout and diet fed. In the first feeding trial, fish fed the sucrose diet performed better than those fed the high-fat diet. Treated fish on the sucrose diet out-performed all other groups with respect to growth parameters, though not significantly $\approx 0$ in all instances. A positive correlation was found between treatment with methy-testasterone and low plasma glucose and low visceral fat ievels in fish fed these diets. In the Eecond feteding trial a molasses ian alternate cambohydrate source). diet, a sucrose diet and a high-fat diet were fed to treated and control fish. Fish in general performed better when fed the two diets high in digestible carbohydrate. Molasses in the fish diet had no adverse affect on growth and results indicated that this sucrose cource might potentially be usad as a feed additive for fish. Treated fish fed the hoghearbohydrate diets in the second trial did not demonstrate the superior performance which was evidenced in the first trial. Fiesults which were obtained from 
these feeding trials are discussed and possible implications for the aquaculture industry are put forth. 


\section{ACKNOWLEDGEMENTS}

I would libe to express my gratitude and appreciation to a number people who were instrumental in completion of this thesis. Foremost, I thank my major professor, Dr Lewis T. Smith, for his guidance in developing this thesis project and his very helpful assistance in following up on the research end of things, through several disheartening complications. His knowledge of general fish culture, genetics and statistics proved invaluatle to me in completing this thesis while his good humor, philosophical insights and interesting story-telling kept morale high. I would also like to thank Dr. Thomas L. Meade for his help in the formulation of fish diets and his advise on the nutritional aspects of the research. In addition, I am grateful to Dr. Meade for serving as a member of my committee, along with Dr. Fichard Fhodes and Dr. Murn Nippa. Dr. Fhodes and Dr. Nippo were very helpful with their editorial corrections of the defense copy of the thesis and their comments and suggestions weighed heavily in the completion of the final, revised product. Dr.

Fichard E. Wolke's training and assistance in diagnosing 
and treating diseases of $f$ ish is appreciated and his good sportsmanship and competetiveness at the T.T. table provided me with many afternoons of intelectual stimulation and exercise away from the rigors of studying. Dr Terance Bradley's insight was most helpful. I am grateful for the work of Sheila Folofsky in processing tissue needed for analysis in my study, and for her patience in training a "J.T." in histological techniques. I appreciate the help of Foster Edgar, who was always happy to lend a hand when one was needed. Conrad's good spirits and willing assistance to all students showed me that good research and contientious teaching can indeed go hand in hand. The moral support and assistance of my fellow graduate students Bernie Eernatoris, Anita George, Karla Johanning, Dan Medina and In Muligan was most helpful and ericouraging. The nurf "hoop" games with Jim and Dan were a pleasant diversion. I am thankful for the support and understanding of my family: Dad, Jane, Kelly, Maureen, Kevin and Brian and Mom in Florida, over the years. My friend Dave gave me Encour agement when I was down.

Most of all, it was the support, understanding and encouragenent of my wife carlene and her belief in me, which gave we the perserverance to complete this thesis. It 15 to her that this thesis is dedicated. 


\section{TABLE OF CONTENTS}

PagE

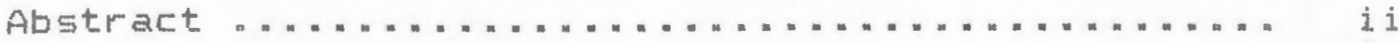

Acknowl edgenents ............................ v v

Table of contents .......................... vi

List of Taties ..................................... vii

List of Figures ............................ ix

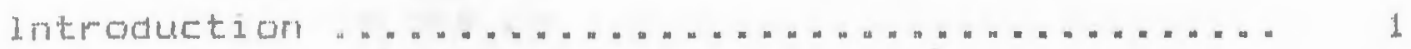

Liter ature Feview ..................................

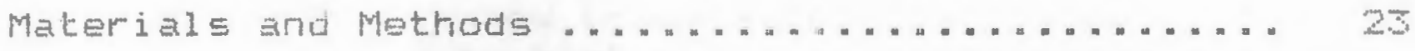

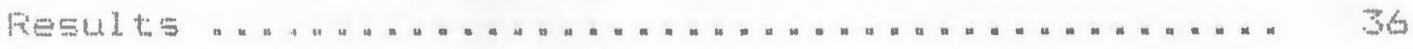

Discussion and Summary ......................... 74

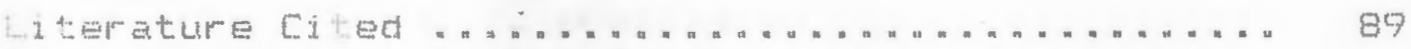

Appendid I. Freeze Branding ...................... 99

Appendi il - Analysis of Varlance for ald Tests . ".106 


\section{LIST OF TABLES}

Table

Fage

I. Dietary fngredients-Trial \#1 ............. 32

II. Energy Content of Diets (Kcal/Kg)-Tr1al \#1 . 3.

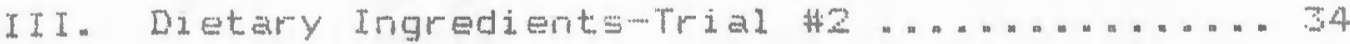

IV. Energy Content of Diets (KCal/kg)-Trial \#2 . . 35

V. The effect of treatment with 17 amethyl-

testojterone on the sexul development of

rainbow trout. "............................ ...

VI. Mean growth parameters for tpeated and zontroi rainbow trout after feeding for 12 wests with high-fat and sucrose diets-

Triel. 相1................................... 4 4

VI. Flesma jiucose and visceral tat levela of

treated and control rainbow erout a ter

Feeding for 12 weeks Hith higli-tat and

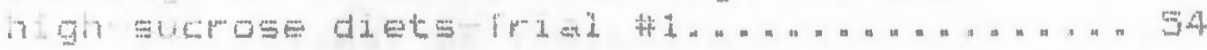

VII. llean growth paraneters for trated and

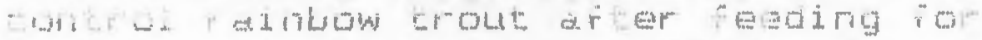

wets = with high-rat, sumbse ard

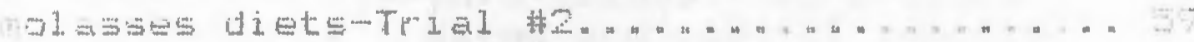

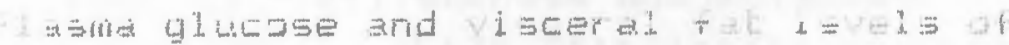

treaked and control raintiow tiout art

teed 199 for 9 . weeks with high rat,

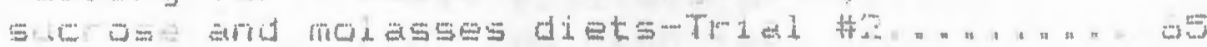




\section{LIST OF FIGURES}

Fiqure

Frage

1. Dverall effect (Trials \#1 sexual development of treatirent with methyltestosterone early in 1 ife.....................

2. Actual gain (grams) of treated and control rainbow trout fed high-fat and sucrose diets for 12 weet:s-Trial \#1....................... 42

3 . Feed conversion (g fed/g gained) and protein conversior (\%) of treated and control rainbow trout fied high-fat and sucrose diets for 12 weetrs-Trial \#1............................... 45

4. Felative gain (gain/initial wt) of treated and control rainbow trout fed high-fat and sucrose diets for 12 weeks-Trial \#1............ $4 \%$

5. Treatment and feeds interaction effect on actual welght gain and feed conversion levels in treated and control rainkow trout fed high-fat and surrose diets for 12 wetes-Trial \#1.........

6. Plasma ghlucose and visceral fat levels of treated and eontrol rainbow trout fed high-fat and Euc ose diets for 12 weeks-Trial \#1........

7. Actual gain (grams) of treated and control ranbow tiolit fed high-fat, sucrose and molasses dlets for 7 weet:s Trial \#2................... bo

8. Feed conversion ( $g$ fed/g ganed) and protein conversion (\%) of treated and control ralribow ticut fed high-fat, sucrose and mol asses dlets for 9 week:s-Trial \#2..................

7. Felative gain (gain/initial wt) of treated and contral rainbow trout fed high-fat, sucrose and molasses diets for 9 weeks-Triel 和........ 66

10. Treatiment and feed interaction effect on actual weight gan and feed conversion in treated and control ranbow trout fed high-fat, sucrose and mol asses diets for 9 weets-Trial \#2......... 


\section{Fiquire}

11. Flasma glucose and visceral fat levels of treated and control rainbow trout fed high-fat, sucrose and molasses diets for 9 weelss-

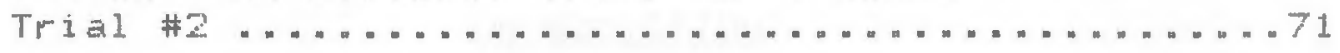

12. Fhoto of yearling rainbow trout, with recognizable mark from freeze-branding apparatus, taken six

weets after branding .............................. 104 


\section{INTRODUCTION}

Eecause the natural diet of wild trout is composed mainly of protein, researchers and aquaculturists have long entertained the belief that salmanids and, to a lesser extent, other cultured species require a high level of dietary protein in order to obtain maximum growth and optimuin feed conversion SScherbina and Tryamkina, 1974; Flakas et al., 1980, Robinson et al., 1980). Early investigators stated that protein levels needed to achieve maxinum growth and feed conversion were as high as $40 \%$ of the diet or greater (Delong et al.,1959; Chance et al., 1964). In nature, salmonids ltilize dietary protein not only for growth !muscle protein synthesis and nitrogen retention) but also to help meet part of the fish's energy need=. In an aquaculture situation, it seems, other components might be incorporated into fish diets which could "Epare" dietary protein and fullfill energy (maintenance and production) demands of the fish. Fish culturists are constarily monitoring new developments in the fish food industry, trying to obtain less expensive feeds which give adequate growth results and feed canversion efficiencies. The addition of lipids in higher percentages to fish diets has shown benifits with respect 
to sparing dietary protein (Kellems and Sinnhuber, 1982). However; quality lipids which may be used in fish feeds are unavailable in some areas of the world and therefore of little practical value. The use of sucrose, a carbohydrate(CHO) easily digested by salmorids and other fish, when incorporated into fish diets should provide a "sparing" action on dietary protein. Sucrose is also readily available in most parts of the world. The use of molesses in fish feeds could also provide a means for formulating a 1 ess expensive diet.

Sucrose, a relatively inexpensive sugar, is $85 \%$ digestible by salmonids (Halver, 1972) and hence may be a good source of energy for meeting the daily caloric requil Enents of the fish. Sucrose, a disaccharide made up of fructose and glucose, is more easily digested by salmonids than other complex CHOs. Fructose may be taken up at tre cellular level and enter directly into the glycolytic pathway without the use of insulin (Stryer, 1981). Blackstrap nolasses, a sugar refinery by-product, maght alsu be a practical source of sucrose and is readily available ir many areas. Molasses, which contains 50-60\% Eucrose, also haj the advantage of acting as a good binder in diet formulathoris.

For a long period of time, diet inanipulation has been utilized in fish culture as a way to improve growth rates and feed conversion and to increase the iarket. size of fish. Within the last decade researchers have increasingly 
turned to the use of hormones and their possible application in fish culture as growth promoters. Both natural (growth hormore, prolactin, thyroid and steroid hormones) and synthetic (synthetic steraids, testosterones and estradiols) hormones have teen used in studies ranging from inducing smoltification in anadromous salmonids to sek revereal and sterilization of salmonids for improvement of growth performance and use in genetic research (Donaldson and Hunter, 1992; Higgs et al., 1982; Smith, 1983). Steroid hormones have been used in both sex control of salmonids cDoneldson and Hunter, 1991; Eillard et al., 1901) and as anabolic agents promoting growth (Hirose and Hitiya, 1968: Higgs et al., 1982). 17a-methyltestowterone (17a-MT), or 17 a-Methyl-4-androsten-17B-o1-3-one, a synthetuc sterold hormone, has been used to entance gonadal development in grey mullet (Weber and Lee, 1985), produce sterility in salmonids (Dorialdson and Hunter, 1982), and cause sex reversal in tilapia (Gwusu-Frimpond and Najhar, 1990. Macintosh Et $21 ., 1985$ ), carp (Foa et al., 1983: Jensen et al. 1983) and Atlantic selinor (Johnstone and Youngson, 1984). Along with these androgeric (sex-reversal and sterility) properties, this hormone has also been shown to be Lseful as ari anabolic agent in fish culture. Dietary incorporation of $172-M T$ promoted growth and improved feed conversion in the American Eel (Degani and Gallagher, 1985), carp (Lone and Matty, 1979) and salmonids (Higgs et a1., 1777. Fagerlund et a1., 1979). Sterile salmonids, 
produced with high dietary levels of 17a-MT given upon onset of feeding, initially show reduced growth wher compared with controls. But as the fish mature, the sterile fish have greater growth and feed conversion efficiency than controls. Sterilized fish need not utilize energy for sexual maturation and instead may put this energy into muscle tissue production and growth (Higgs et a1., 1982; Smith, 1983). Interestingly, the 17a-MT-treated fish show impraved growth performance over their control counterparts not only during this se: ual maturation period but throughout the entire adult life of the fish cooraldson and Hunter, 1992; Schreck and Li, 1983. A possible explangtion of this phenomenon may be that treatment with high levels of $: 73-M T$ early in 1 ife somehow disrupts part of the bicsyrthetic pathways which play a role in metatolism of the fish. Alternatively, thic might suggest that these homones, present in higher levels in untreated fish, while influenting sexual maturetion and development, could also suppress the natumal growth potentdal of these fisin.

The objectives of this study were two-fold. The first was to de elop a practical diet which provided an inexpensive, Ltilizatle CHO source for use in Ealmomid fand possibiy other fish) culture. The purpose here was to determine if CHO provided in the proper form in salmonid diets stimulated growth and affected feed conversion efficiency: This research wa ghed to determine if bath 
sucrose and molasses are feasible additives to any fish diet formulation if provided in correct amounts. The second objective of this work was to study the growth response of salmonids which have been treated with high levels (5omg/kg of diet) of $17 a-M T$ at a young age, to high-fat and high--CHO diets. The performance of treated/ sterile fish was compared with non-treated fish given these high-CHO and high-lipid diets. Fesults of these studies and implications for the fish feed and aquacuiture industries will be discussed. 


\section{LITERATURE REVIEW}

The findings of early researchers led to the development of commercial fish feeds which are very high $(340 \%)$ in crude protein and low in digestible carbohydrates (CHO) (Delorig et al., 1959; Chance et al., 1964; Shcherbina and Tryamkina, 1974: Kanid yev and Stlyarov, 1979; Erown et al. 1935). It has been observed, though, that the quantity and quality of indispensible amino acids available in the diet is more important than high amounts of crude protein. (Shanks et al, 1962; Dupree and Halver, 1970, Plates et al., 1980: Robinson et al., 1980). Therefore, the absolute jmount of crude protein might be reduced in dlets if adequate levels of essential aminc acids were Ineluded in the diet of each cultured species. However, commercial pelleted diets continue to te made with high crude protein levels along with low or high levels of undtgestible CHO fŔangens/Zeigler fish feeds, 1994: Martins salmonid feeds, 1984; Stinson Traut Line feeds, 1984).

DSSilva and Ferera (1985), usirig young Tilapia nilotica, found that growth on diets containing only $28-30 \%$ protein was consistently better than higher protein diets. while feed corversion efficiency was decreased at protein levels above 30\%. Machiels and Henken (1985), worting with the African catfish (CIarias gariepinus), recommended that 
an optimum proteinfenergy ratio be pursued when formulating diets. Fieper and Ffeffer (1980a) showed a positive relationship between high energy (sucrose)/lower protein formulations when varying protein and energy levels in rainbow trout (Salmo giardneri) diets. They showed improved protein efficiency ratio (FER) after decreasing the protein content and increasing the proportion of sucrose in the diet. Hence, sucrose had a protein "sparing" action in the diet.

Because the natural diets of fish are composed not only of protein but also lipids, researchers have investigated the use of 1 ipids in salmonids and other fish diets as an energy source. In carp (Cyprinus carpio), Nagal and Iteda (1973), when comparing the practicality of using ipids versus CHOs as a dietary energy source, found the rate of metabolism for lipids was twice as fast as that for complex CHO. Since Castell et al., (1972) identified the essential fatty acids, much work has been done varying the lipht and essential fatty acid levels in salmonid fish diets. Up to $24 \%$ salmon oil produced improvement in growth and feed conversion when provided in raintow trout diets (Lee and Futram, 1973; Feinitz et al., 1978). El11s and Smith (1984), ir studying digestibility and essentiality ln fish, demonstrated the quality of the fatty acid content of fish oils and other oils which may be used in fish diets. The value of merhaden oil in diets of Florida pampano 
(Trachinotus carolinus) was studied and an optimum dietary level of $9 \%$ menhaden oil was obtained for this fish

(Williams et al., 1985). Above and below this optimum dietary level, feed conversion was less efficient. Lipids which are less expensive and of lower quality than these highly unsaturated oils though, yield poor results when lused an fish diets. Incorporation of beef tallow into the diet of tilapia resulted in poor growth and poor utilization of this lipid (Stickney and McGeachin, 1984). In a study using 25-45\% herring oil fed with gelatin bound proteins, Kellems and Sinnhuber (1982) stated that increased amounts of oil in the diet had a positive high relition to feed conversion efficiencies. However, these athors aiso noted that the overall desirability of the Fish, as determined by a taste periel, was lower for those feu diets with high levels of herring oil. The use of lipld levela greater than $25 \%$ in trout diets leads to licreased deposition of body fat kellens and sinnhuber, 1982:. IL IS evident that the use of high quality lipids in fish feeds might be necessary to a 1 imited extent in order to provide essential fatty acids. The addition of high quantuties of quality 1 ipids (fish oils, seed oils) to Iish diets though, may not be feasible due to taste intolerance, Inordinate deposition of body fats or, as may be the ease in inary areas, high cost or inavailability of quality 1 ifld lngredients. 
The inclusion of CHO in fish diets has, for a 1 ong period of time been neglected or used simply as a filler. A number of researchers have reported that fish in general and salinonids in particular were poor utilizers of CHO (Austreng et al., 1977; Hilton et al., 1982; Andersan etal., 1984). Mare recently studies invalving incorporation of different carbohydrates into fish diets has given room for optimism. Spannhof and Flantikow (1983) showed that starch content of rainbow trout feed and feed digestibility are negatively correlated. The same study demonstrated that dextrin, a starch product with ar advanced degree of hydrolysis, improved digestion when included in the diet. These authors concluded that crude starch in trout diets reduces amylase activity in the intestinal. juices and that crude starch contents of about $20 \%$ innibits CHD absorption. Therefore, the use of crude starch and complex CHDs in salmorid diets yields poor performance at best. Edwards et al (1977) found that praspects for selectively breeding strains of rainbow trout which are better able to utiliae carbohydrate are not promising. Austreng et al (1977) reported similar results and added further that reduced conversion efficiency of protein and energy, and inferior fish growth on high CHO diet: might make the use of large amounts of CHO in trout diets unfeasible. Fresumably then, the only way to incorporate high levels of CHO in fish diets is to provide 
it in forms which are utilizable by fish or by hormonal manipulations which will allow for better absorption and digestion.

Nagai and Ileda (1975) suggest the inferiority of carbohydrate as an energy source in carp and also demonstrated impaired glucose utiliaation in these fish. However, Anderson et al (1984) showed improved growth in the juvenile tilapia (Oreochromis riloticus) as the level of glucose, sucrase, dextrin or starch was increased from o-40\% of the diet. Glucose at higher levels in the diet spared less protein energy than dextrin or sucrose. At levels above $10 \%$ sucrose produced greater protein retention than glucose, indicating that this disaccharide has greater potential for sparing protein in complete rations. According to Hilton and Atkinson (1982), weight gain was sigrificartly reduced in trout reared on diets highest (21\%) in the avaliable CHO, cerelose (alpha-glucose), as compared to 1 uwer dietary levels of this synthetic sugar. These authors concluded that trout have a limited ability to adapt to increased dietary $\mathrm{CHO}$, and that a level in Excess of $14 \%$ of the diet is not efficiently utilized. Hilton et al (1982) recommended that the maximum tolerable level of cerelase in selmonid diets appears to be dependent upon the protein, 1 ipid, and overall energy content of the diet, and that higher levels of cerelose (up to $25 \%$ in the diet may be efficientIy utilized. In a study involving the 
digestibility of starch by rainbow trout, Bergot and Breque (1985) concluded that starch becomes a valuble source of energy when its digestibility is enhanced by

gelatinization. Crude native corn starch (non-gelatinized) in diets gave poor results. In another study, a $30 \%$ glucose diet promoted the best weight gain, feed conversion and protein efficiency when compared with starch diets and a 15\% glucose diet (Bergot,1779a). The results of this study, in contrast to some mentioned earlier, indicate that trout can tolerate a higher level $(\gamma=30 \%)$ of glucose in their diet.

other studies involving increasing proportions of sucrose and gelatinized maize starch in diets for rainbow trout have shown that there may be possibilities for CHO use in samonid diets. Fieper and Fifeffer (1980a), in a study on the comparative efficiency of utilization of gross Energy using different CHOs, proteins and lipid sources, found that in rainbow trout, sucrose was the most efficientiy used energy source, with sunflower oil, gelatinized starch and glucose followirg in descending order. From this study it was concluded that glucose and getatinized starch may be used enargetically in trout as efficiently as sunflower oil and may be included in diets for the purpose of sparing dietary protein. In fact, it was suggested that CHOs, as compared with fat, showed a certain superiority with respect to sparing dietary 
protein. These CHOS (sucrose and gelatinized maize) could be incluided in diets at levels up to $30 \%$. The fact that sucrose and gelatinized maize were utilized more efficiently than glucase suggests that digestion is not a limiting factor for utilization of these CHOs at these levels. This may also reflect some negative physiological effects of a sudden large flux of glucose into the fish's metabolic system.

The same authors in another, similar study \&Fieper and Ffeffer, 1980b) showed an improvement in food conversion when sucrose content was above $36 \%$ of the diet and protein level below 40\%. Frotein efficiency ratio (PEFi) was also improved by increasing the proportion of sucrose in the diat. The study gave further evidence that both sucrose and gelatinized maize starch may be used in trout diets to frovide a relatively large percentage of the metabolizable energy needed and can spare dietary protein. This spared dietary protein in turn can be used in tissue building processes. Pieper and Ffefrer (1790b) further state that the use of these CHOS as substitutes on an energetic basis does not produce a great increase in body fat content, unlike the use of lipids, which do cause a proportionate increase in fish body fat. This may be of great interest from a consumer point of view. To this date, no use of other, sucrose-containing carbohydrates such as molasses or brewers solids has been reported, but 
these have potential for use in fish diet formulations in the aquaculture industry.

Salmonids, because they are carnivors, cannot efficiently Litilize most dietary CHO additives. This is due to poor digestion of crude and complex CHOs, high circulating levels of cortisol and low levels of insulin Strange et a1., 1979; Wagner and Mckeown, 1982; Specker and Schrect, 1982; Bry, 1982: Ablett et al., 1993). The biological role of cortisol in fish and other vertebrates is to promote $q 1$ cuconeogenesis and enhance catabolic activity (Palmer, 1966: Storer, 1967: Hendricks et al., 1994). High cortisal levels reduce the ability of the fish to effectively Litilize and metabolize CHOS due to reduced insulin levels (Eutler et al. "1969; Pickford et al., 1970; Strarge et al., 1979: Leach and Taylor, 1982: Bry, 1982: Ablett et al., 1983; Carneiro and Amaral, 1983). By reducing blood plasma cortisal levels, insulin may increase, allowing for better utiliaation of blood glucose and dietary glucose sources for eriergy needs (Tashima and Cahil1, 1958; 0ttalenghi et al., 1982; Furlichi and Yone, 1982a; Furuichi and Yone, 1982b). Fatent (1970), working with the elasmobrarich dogfish (squalus asanthias) showed insulin to be a potent hypoglycemic agent while cortisol and corticosterone produced hyperglycemia when injected. This worl; also indicated that cortisol was an effective gluconeogenit agent in the shark. 
Cortisol affects growth by acting on skeletal muscle causing an increase in protein catabolism and decreased protein synthesis, which in turn increases amino acid availability to the liver for gluconeogenesis (Hendricks et a1.,1984). These authors showed that young bulls grow faster than older heifers due to lower circulating levels of cortisol. Falmer (1966) demoristrated net loss of weight after 24 hours, in normally feeding rats which had received a single injection of cortisol. Daily rhythm of weight gain was al tered. It seems clear that high cortisol levels, which is the case in fish, has a potent negative effect on nitrogen retention, protein synthesis and CHO utilization and metabolism. In a study on gluconeogensis in rainbow trout (s. gairdreri), it was shown that hyperglycemia was due to gluconeogensis, confirming the fey role of this process in trout (Morata et a1., 1982). Bry (1982) gave evidence for a post feeding peak in plasma cortisal Levels in well adapted rainbow trout. This suggeste that cortisol plays a key role in digestion and metabolic processes, specifically CHO and protein metabolism. A reduction in circulating plasma cortisol levels might timprove CHO (glucose) uptake and metabolism through increased circulating insulin levels. This would also reduce the gluconeogenic effects of this hormone, improve nitragen retention, and increase t1subu protein synthesis. Cortisol, a glucacorticoid, promotes 
gluconeogensis and catabolic processes and inhibits anabolic ones, whereas insulin acts to promote anabolic processes and inhibit catabolism in muscle, 1 iver and adipose tissue. Insulin also stimulates glycolysis, increases the rate of protein and glycogen synthesis, and promotes the entry of glucose, some other sugars and amino acids into muscle and fat cells (Stryer, 1981).

Cortisol is produced in the adrenal cortex, cholesterol being the principal precursor of all the adrenal cortical hormones, including testosterone (Stryer, 1981: Allaben, 1982). Cortisol synthesis follows one pathway in immature individuals and another in mature individuals, with common precursors occuring in bath pathways. Corticosterone occupies a separate pathway altogether, after the precursor cholesterol is reached. Testosterone has some common precursors and follows an identical route for a tine with the cortisol pathway utilized by adults (Allaben,1982). It has been shown that high circula-ing levels of testosterare in the blood coincides with low levels of cortisol in the catfish, Heteropneustes fossi1is (Sundararajet a1., 1982; Lamba et al., 1983). These authors also showed that during preparatory and prespawning periods, cortisol increased Gramatically in these fish, and that highest levels of plasma cortisol accur in recrudescing fish.

Fish which had been hormonally sterilized would not 
be subjected to these pre- and post-spawning cortisol highs and would, therefore, not be subjected to cortisol during these periods. All energy could be diverted to maintenance and anabolic processes, instead of spawning preparation and recovery. In rats, high testosterone levels reduce the production of cortisol binding globulin (CBG) and hence, reduce the amount of free cortisol released into the bloodstrean (Gal a and Wesphal, 1965: Allaben, 1982;). Ferhaps the high levels of 17 alphamethyltestosterone (17aMT) which causes sterility when fed to young fish might aso rave some effect (permanently) on production of CEG, or a similar cortisol binder in fish, and reduce the circulating levels of cortisol in the blood. It is also possible that a high influx of testosterone (or 17aMT) in voung trout for such a long period of time (900' days) might somehow damage or destroy the biosynthetic pathways which produce the glucocorticoids, hence reducing the amount of cortisol produced for the lifetime of the fish. Methyl testosterone (MT) has been used in

aquacul ture research for various reasons and has produced different results, depending upon dosage and mode of application. Svnthetic testosterones were first used in fish research for androgenic purposes or genetic sex manipulations. 17 aM has been shown to enhance spermatogeriesis in the steelhead trout (5ower et al. "1983) and spermation in the grey mullet (Weber and Lee, 1995). 
Through treatment with this hormone by implantation or oral administration in the diet at low levels $(3.0-5.0 \mathrm{mg} / \mathrm{kg}$ feed), sex reversal has been demonstrated in catfish (Goudie et al., 1983), tilapia (Dwusumfimpong and Nijjhar, 1981: Macintosh et a1., 1985), carp (Jensen et al., 198.: Rao et al.,1983) and salmonids (Donaldson and Hunter, 1982; Schreck and Li, 1983). This treatment produces sex-inverted male (previously females) fish which can then be mated to normal fimales to produce all famale progeny. This has been achieved in Atlantic salmon (Johnstone and Youngson, 1984). This technique may be implemented by fish farmers to produce monosex cultures needed for specific uses. Sterility tias been produced in salmonids by feeding higher lovels of $17 \mathrm{aMT}(40-60 \mathrm{mg} / \mathrm{kg}$ ) in the diet (Billard et a 1., 1791; D+11ard et al., 1992; Donaldson and Hunter, 1982; Solar et al., 198. Schreck and Li, 1983). These sterile fish, after maturity, become easier to handle and prove to be more hardy than untreated fish (Smith, 1983). They also show improved growth rates over untreated fish of the same age and stock (Donaldson and Hunter, 1982; Higgs et a1., 1982).

Androgens in general, and testosterones (natural and synthetic) in particular, act as anabolic agents to Increase nitrogen retention and utilize protein and amino acids from the diet to build muscle tissue (Hirose and Hibiva, 1968: Higgs et al., 1977; Stryer, 1981; 
Dasmatiapatra and Medda, 1982; Lone and Matty, 1982). In the rat, subcutaneous injections of testosterone produced an increase in protein and amino acid synthesis and increased overall weight as compared to controls (Deloecker, 1964). The same effect was demonstrated in rabbits after surgical implation of testosterone by Grigsby et al (1976). Testosterone improved gain and feed efficiency and increased muscle synthesis rates.

Injections of testosterone proprionate to the catfish (Heteropneustes tossilis) produced an anabolic effect on CHO metabolism. This was indicated ty an increase in liver glycogen, resulting from its increased synthesis andfor less breakdown, in both male and female fish (Dasmahapatra and Medda, 1982). In the rainbow trout, Hirose and Hibiya (1968) produced a 1 imited anabolic growth response through intra-muscular injection of 4-chlorotestosterone, though a more poterit response was produced in the goldfish. Lone and Matty (1992) have shown increased growth rates and more efficient feed conversions with oral administration of 11 -ketotestosterone to carp (Cyprinus sarpio) at levels of $1.0-10.0 \mathrm{mg} / \mathrm{kg}$ of diet, as compared to carp not fed this steroid. Eut $17 a 1 p h a-m e t h y l$ testasterone (17aMT) has been more widely used as an anabolic agent to promote growth in fish than any other of the synthetic anabolic sterojds.

Again working with carp, Lone and Matty (1930), 
after feeding for 90 days with different levels of $17 a M T$ in the diet $(1.0-10.0 \mathrm{mg} / \mathrm{Kg})$, showed a positive growth response. They also reported a significant increase in total protein and FNA, and in the protein/DNA ratio in liver, kidney, brain and muscle tissue. These authors telieve that 17 aMT induces growth by acting probably in three different ways: (1) 1ncreased food conversion, activation or sezretion of other endogenous anabolic hormones, and (3) direct effect of 17 aM on gene expression in muscle cells. The belief here is that feed conversion efficiency is improved due to an increased ability of the fish to utilize and metabolize CHOs. In the American eel (Anguilla rostrata), dietary 17 aMT at low levels (1.0 mg/kg) Sigrificantly increased mean weight and improved feed conversion compared with controlscDegani and Gallagher, 19a5). Using higher levels of $17 a M T(10.0 \mathrm{mg} / \mathrm{kg}$ diet), the same authors produced an increase in mean body weight in adult eels.

H1gys et al (1977) reported enhariced growth in yearling coho salmon (oncorhyrchus kisutch) with administration of 17 aMT alane in the diet ( 1 mg/kg) and also when $17 a M T$ was given in combination with bovine growth hormone and L-thyrovine. In a study varying dietary protein and 1 ipid in conjunction with 17 aMT supplementation (1ppm), 17aMT significantly enhanced growth of juvenile coho salmon regardless of diet composition. Groups fed 
17aMT diets also showed an increased protein efficiency ratio (FEF) (Fagerlund et al., 1983). These authors demonstrated enhancement of thyroid activity in fish fed 17 aMT-treated diets, as did Lone and Matty (1980) in carp. This may have been due to reduced circulating levels of cortisol. Specker and Schreck. (1982), working with smoltification in coho salmom, reported that during early smolt periods wher cortisol levels are lowest, thyroxine levels are at their peak. Spieler and Noestie (1984) also demonstrated that concentration peaks of cortisol and thyroxine were inversely related when they worked with photoperiod and feeding schedule in goldfish. Hunt and Eales (1979) showed that testosterone proprionate has a marked effect on increasing thyroid activity and the production of thyroid harmones, $T=$ and $T_{4}$. Then, it appears there might be indirect evidence that incorporation of 17 aMT $1 n$ Ealmonid diets might somehow reduce circulating cortisal levels, thereby stimulating growth through the effect of these endogeneols anabolic hormones and through better feed CHO utilization. 17aMT was proven as a growth promoter in a coho salmon hatchery, and feed utilization was improved in fry fed $1 \mathrm{mg} 17 \mathrm{MMT} / \mathrm{kg}$ diet for a seven month period (Fagerlund et al., 1979). Improvement in growth and feed conversion has also been demonstrated in rainbow trout and Atlantic salmon with incorporation of 17 aMT into diets (Higgs et al. "1992). 
The use of $17 a M T$ in fish culture operations is a highly feasible one because this synthetic hormone is relatively inexpensive, only small amounts are required, they are used successfully in sex control studies, and benefits with respect to weight gain and feed conversion are substantial. It has also been shown that this hormone is safe to use and is eliminated (cleared) from tissues in a short period of time after application has ceased. In worl done with coho salmon, ten days after steroid withdrawal from diets, concentrations were 1 g g/g or 1 ower in blood and 16 other tissues (Fagerlund and McEride, 1978). In tilapia and rainbow trout juveniles, $99 \%$ of radioactively labeled 17 aMT was eliminated from al tissues within 100 hours of omission of the hormone from the diet, aftar feeding at a level of $40 \mathrm{mg} / \mathrm{kg}$ of diet Sohnstone et a1., 1938. Thus, fish fed 17 aMT at an early age to Eliminate sex characteristics would contain no residues of the hormone when reaching market $5 i z e$. Thöe given 17 aMT aj adul fish to produce anabolic effects would first have to be "cleared" of 17 aMT for a short time before marketing could occur. At this time 17 aMt has not been officially sanctioned for use by the U.S.D.A. in hatchery and fish culture operations, but this may change soor. Sterolds and antibiotics have long been used in the beef, swine and poultry industries and it is clear that 17 MMT Lse would be a boon to al1 aquacultumists. 
The present research was conducted to study the performance of rainbow trout, treated with high levels of $17 a M T$ at a young age, on a high-carbohydrate diet versus a high-lipid diet. The reasoning here is that fish which have been sterilized with high levels of $17 a M T$ at an early age will respond better to a diet which is high in digestible CHO. These steriliaed fish have consistently out-performed control fish of the same age under ideritical coriditions as the fish mature. It is thought that perhaps the high dose of 17 aMT has precipitated an inability of the fish to produce high levels of cortisol throughout its lifetime, thereby enhancing the ability of the fish to utilize dietary $\mathrm{CHO}$ and allow for increased anabolic effects of thyraid hormones also. Fieduced cortisol levels could also increase the role of insulin in salmonids, leading to better glucose uptake and increased glycolysis for the production of energy. The benefits of 1 ow cast, highly digestible CHOs in salmonid diets will be discussed in the context of all other pertinent factors. 


\section{MATERIALS AND METHODS}

\section{Experimental Animals}

Fainbow trout (SaImo gairdneri), directly after hatching, were fed diets containing 50mg of 17-methyl testosterone (17aMT) per kilogram of feed for $900^{\circ}$ days (water temperature in ' $C$ number of days) to induce sterilization (Donaldson and Hunter, 1982). These fish were held in a large tank with a $90 \%$ water reuse system at the East Farm Aquaculture Center (EFAC) of the University of Fhode Island until needed for experimental purposes. At the age of six months for the first feeding trial, and ter. months for the second feeding trial these sterilized fish were ther transferred, in appropriate numbers, to smaller bigassay tanks which operated with a 100\% water flow-through system. At this time, untreated (control) rainbow trout, which had been held in an identical situation to the treated fish, were also transfered to the experimental tanks. Sterilized (1.7aMT-treated) and control (non- treated) fish were of the same spawning group and therefore the same age at the time of the experiment. All experimental fish were held in a 100\% water flow-through 
system throughout both feeding trials. All fish were spawned, hatched and raised at EFAC and were fed identical diets until the experiments began. Treated fish were distinguished from control fish by clipping of the adipose fin of treated fish prior to placing in experimental tank:s for both feeding trials.

At the termination of both feeding trials, fish were sacrificed and a gross visual inspection of sexual organs (gonads) was made. Determination of the effect of 17 aMT treatment sgiven in feed to young fish at the onset of feeding) was made in comparison to control fish of the same age and described according to certain criteria. The three descriptive categories were: 1.) sterile- no evidence of goradal material, or gonadal material so rudimentary that males and females could not be differentiated;

2. Hunderdeveloped male or female-gonads were underdeveloped for the age of the fish (as compared to controls), difficult to differentiate between males and females, gonads very rudimentary and probably non-functional. and 3.) fully developed male or female-gonads large and fully developed, sexes easily differentiated and identified, eggs Easily seen and milt often present. A sample of treated fish ( 35 ) and control fish (15) of the same spawning group as those used in both feeding trials were examined histologically to determine the effects of treatment at the CEIlular IEVEl. 


\section{Experimental Desian}

After transferring fish from larger tanks to sinaller experimental tanks and prior to the start of both feeding trials, fish were allowed to acclimate to new surroundings for 10 to 14 days. Six tanks (200 1 itre capacity) were used for each feeding trial. For the first trial, 20 rainbow trout ( $s$. gairdreri) were placed in each tank, 10 of which were treated fish and 10 control fish. This was done to eliminate any tank effect during the course of the trial. Throughout the first trial, which lasted 12 weeks, tanks 1-3 were fed a diet high in fat while tank:5 4-6 were fed a diet righ in sucrose (as a digestible carbohydrate). Feed for each tank was weighed out daily and fed according to the required percentage of body weight based on fish size and water temperatures. Feeding levels ranged between 1.5 and $3.0 \%$ of the live weight daily. Fish were fed twice per day at low feeding levels and 3 times per day at high feeding Ievels. At three week intervals during the trial fish were anesthesized (with MS-222), weighed, and measured and average gains were calculated for each group (17aMT-treated and control) and for each tank. During the first feeding trial water temperatures ranged from $6^{\circ} \mathrm{C}$ to $12^{\circ} \mathrm{C}$.

On the days of the sixth and ninth week 1 ength and weight measurements, are treated fish and one control fish from each tank was bled. Fish were fed four hours prior to 
bleeding. Fish were returned to appropriate tanks after bleeding. Elood was taken from the cardinal vein lcaudal area) with a syringe coated with heparin. Flasma was obtained for each fish through centrifugation and separation from cells. Values for plasma glucose and ammonia were obtained through Sigma diagnostic procedures (\# 15-UV for glucose, \#170-UV for ammonia) for the quantitative enzymatic determination in plasma with the use of a BoL spectrophotometer (Spectronic 70). Results were compared for each tank and each fish. Upon termination (12 weeks, each fish was weighed, measured, bled with heparinized syringes and sacrificed. Feed conversions were calculated at specified intervals and at termination. Fish were starved for more than 12 hours prior to bleeding. Blood was taken and plasma obtained with the same technique as was used earlier in the trial. After sacrificing fish, visceral fat of ach fish was weighed for comparisons between groups and the sex of each fish was determined in order to judge the effect of the 17 aMT treatment administered earlier in life. Blood glucose and blood ammonia was then determined for each fish in each tank: using Sigma diagrostic procedures (\#S 15-UV and 170-UV) and spectrophotometer as before. For the first feeding trial fish were not marled individually and therefore individual differences for actual growth and relative growth (gainfinitial weight) could not be determined. Dnly total 
values and average values for each group and each tanl: could be analyzed. Data was analyzed using Analysis of Variance (ANOVA) and mean separation techniques (Least Significant Difference- LSD) at. 05 level of significance.

For the second feeding trial, 24 rainbow trout were placed in each tank, 12 of which were treated fish and 12 of which were control fish. AT the time of initial measurements, each fish was marked using a freeze-branding technique (Mighell, 1969: Sorenson et al.,1985) to allow for individual differences to be obtained and individual statistical analysis techniques to be used. Four brand orientations and three locations on the fish were used, giving 12 recognizable brands per tank. Taking into account that treated fish were distinguishable by their sever"ed adipose fin, this facilitated the use of 24 different brands (ore per fish) for each tant.. The brandirg mechanism was easily built and the brands applied after fish were anesthesized (see appendix I).

In the second feeding trial, a molasges diet was 1ncorporated, with mol asses providing the digestitle CHO as opposed to sucrose. In this trial two tanks were fed a high fat diet (tanks 1 and 4), two tanks were fed a high sucrose diet (tanks 2 and 5 ) and two tanks a high molasses diet (tanl:s 5 and b). As before, food for each tarik was weighed out daily and fed according to the required percentage of body weight based on fish size and water 
temperature. Feeding levels ranged between 1.5 and $3.0 \%$ of the live weight daily and fish were fed two or three times daily. During this trial length and weight determinations were made every three weeks from the start to finish. Fish were anesthesized, weighed and measured and returned to respective tanks as soon as possible. Erands were identified at this time in order to show gains of individual fish. Feed conversior was calculated and feeding percentage readjusted for each tank. During the second feeding trial water temperatures ranged from $8^{\circ} \mathrm{C}$ and $14^{\circ} \mathrm{C}$

During the sixth and ninth week length and weight measurements, blood was taken from two fish cone treated, one control) per tank and plasma obtained and analyzed for glucose and ammonia as was done in the first trial. Results were again compared for each tank and each diet. As with the first trial, upon termination (12 weeks) fish were weighed, measured, bled from the caudal vein with heparinized syringes, and sacrificed. Feed conversjons, for the last growth period and overal1, were calculated. Analysis of growth data and calculation of overall feed conversiors for the three feeds and treated versus control fish was done at nine weeks for the second trial. This was dore because after nine weeks fish tecame anorexic kpoor appetitel and sick, with a few deaths occuring. Visceral fat was weighed for each fish to compare results between 
diets and treatments and fish were sexed to determine the effect of 17 aMT treatment given to the fish earlier.

Flasma glucose and ammonia was once again determined and results used for statistical comparisons. Eecause of individual fish records, growth data could be analyaed more completely by computing actual and relative growth rates (gain/initial welght) for each fish. This and other data was analyzed through ANDVA and LSD methods.

\section{Feed Formulations}

Feeds were prepared using a ground herring fish meal "cake" product Ssupplied by Stinson Canning Co., Eath, Maine, 1784). This herring cake was pre-treated with preservative: and an anti-oxidant (santoquin) prior to use. Part $(1 / 2$ to $2 / 3)$ of this initial ground herring was washed with commercial grade hexane in order to extract fat from the product. The hexane was then decanted and the remaining product allowed to desolventize at ambient temperature, hence reducing the fat content of the ground herring. These high and low-fat ground fish products were then used as a base to which other ingredients were added. In the first feeding trial ground fish, casein, fish oil, alpha-cellulose (as a filler), water and gelatin (as a binder; were the ingredients used in both diets, in varying amounts. Granulated sugar was used as a source of Eucrose 
in the high sucrose diet (Table I). To both formulations vitamin ic (as ascorbic acid) and thiamine (HCL) were included. All components of the diets were mixed (1kg/batch) with a Hobart automatic mixer (Model \# c-100-T) for 10-15 minutes, a period long enough to blend all ingredients evenly. The mixture was then extruded through an appropriate sized die to create the desired pellet size, and fed at the required level. Diets were calculated and formulated to be isocaloric and isonitrogenous (Table II). In the secand feeding trial a diet with a high molasses content was compared with the high fat and high slicrose diets. To facilitate the formulation of a molasses diet a ground fish base product was needed which was very high in protein content and low in fat and moisture content. This ground fish product was made by grinding up whole herring and treating with proprionic and acetic acids (as preservatives) and an anti-oxidant (santoquin) to prevent oxidation of fats. The resulting high-fat fish meal was then mechanically pressed and air dried to reduce moisture, followed by washing with hexane several times to extract muct of the fat. This produced the high protein, low fat and low moisture fish meal base to be used in the molasses diet formulations. In the second feeding trial, all of the diets contained ground fish meal, casein, fish ail and a tinder (carboxy-methyl cellulose). To the high fat and sucrose diets water was also added, and 
alpha-cellulose was used as a filler in the melasses diet. Granulated sugar in the sucrose diet and "blackstrap" molasses in the molasses diet were added in an amount to provide an equal number of calories in both diets. All dietary ingredients (Table III) were mixed and extruded into feeding pellets of the appropriate size, as in trial \#1. All. diets were isonitragenous and isocalorit (Table IV). 
Table I - DIETARY INGREDIENTS - Trial \#1

\section{High-Fat Diet}

Inaredients herring meal * casein gelatin herring ail sucrose a-cellulose water

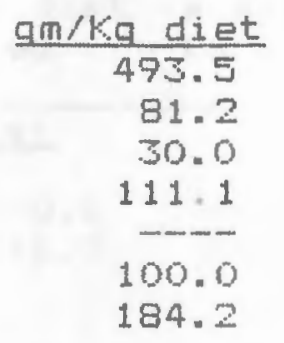

\section{Sucrose Diet}

\section{total}

1000

$40.0 \%$

protein

lipid

carbohydrate (sucrose)

a-cel I UI DSE

water

other**
$24.1 \%$

$0.0 \%$

$10.0 \%$

$18.4 \%$

$7.5 \%$

1000

$40.0 \%$

$15.0 \%$

$23.5 \%$

$5.0 \%$

$5.3 \%$

11. $2 \%$

* = herring meal cake (HMC) compositions (given below)

$\begin{array}{lcc}\text { inaredients } & \frac{\text { high-fat HMC }}{60.8 \%} & \frac{\text { low-fat HMC }}{64.4 \%} \\ \text { protein } & 26.4 \% & 12.7 \% \\ \text { moisture } & 11.4 \% & 14.3 \% \\ \text { ash } & 1.4 \% & 7.6 \%\end{array}$

**-includes water, ash, etc. from herring ineal 
Table II - ENERGY CONTENT OF DIETS $(\mathrm{Kcal} / \mathrm{Kq})$ Trial \#1

\begin{tabular}{|c|c|c|c|c|}
\hline - & $\begin{array}{l}\text { gm/kg } \\
\text { of } d i \in t \\
\text { fed }\end{array}$ & $\begin{array}{l}\text { grams } \\
\text { available } \\
\text { to fish }\end{array}$ & $\begin{array}{l}\text { energyt } \\
\text { gram } \\
\text { (Kical) }\end{array}$ & $\begin{array}{l}\text { total } \\
\text { energy } \\
\text { obtained (kcal) }\end{array}$ \\
\hline High-Fat & Diet & & & \\
\hline $\begin{array}{l}\text { Protein } \\
\text { fat } \\
\text { total }\end{array}$ & $\begin{array}{l}400.0 \\
241.0\end{array}$ & $\begin{array}{l}400.0 \\
241.0\end{array}$ & $\begin{array}{l}3.9 \\
9.0\end{array}$ & $\begin{array}{l}1560.0 \\
2170.0 \\
3730.0\end{array}$ \\
\hline Sucrose & Diet & & & \\
\hline $\begin{array}{l}\text { protein } \\
\text { fat } \\
\text { sucmose } \\
\text { total }\end{array}$ & $\begin{array}{l}400.0 \\
150.0 \\
235.0\end{array}$ & $\begin{array}{l}400.0 \\
150.0 \\
200.0 *\end{array}$ & $\begin{array}{l}3.9 \\
7.0 \\
4.1\end{array}$ & $\begin{array}{r}1560.0 \\
1350.0 \\
820.0 \\
3730.0\end{array}$ \\
\hline
\end{tabular}

* = sucrose is only 85\% digestible by salmonids 
Table III - DIETARY INGREDIENTS - Trial \#2

Diets-y

High-Fat

Sucrose

Mol asses

\section{Inaredients (am/Ka diet)}

$\begin{array}{lr}\text { herring meal } & 500.0 \\ \text { casein } & 149.0 \\ \text { herring oil } & 170.1 \\ \text { sucrose } & - \\ \text { molasses } & - \\ \text { binderz } & 10.0 \\ \text { a-cellul ose } & -170.9 \\ \text { water } & 170.9\end{array}$

\begin{tabular}{r}
466.5 \\
149.0 \\
100.5 \\
258.2 \\
\hline 10.0 \\
15.8
\end{tabular}

450.0

50.0

5.1

420.0

10.0

16.9

water

1000

1000

1000

\section{total}

$35.0 \%$

$24.1 \%$

lipid

carbohydrate

(sucrose)

a-cellul ose

water

other 3

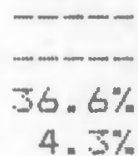

$4.3 \%$
$3.5 \%$

14. $1 \%$

$25.8 \%$

$20.5 \%$
$4.8 \%$
$5.5 \%$

$14.1 \%$

$25.2 \%$

$1.7 \%$

$15.4 \%$

$8.6 \%$

$1=$ mol asses contains"60.0\% Sucrose, $5.0 \%$ protein and 26.0\% moisture.

$z=t h e$ bindar, carboxy-methyl-cellulose, is added dry, directly to each diet.

s=includes water, ash, etc. not accounted for.

4 - compositions of herring meal cale used in:

ingredients

high-fat diet

protein

fat

moisture

ash $(\because)$

$45.2 \%$
$14.2 \%$
$39.0 \%$
$3.6 \%$

$4.5 \%$

$3.6 \%$ sucrose

diet

$46.3 \%$

$8.7 \%$

$40.0 \%$

$5.0 \%$ mol asses

diet

$6.1 \%$

$19.6 \%$

10. $0 \%$

$7.4 \%$ 
Table IV ENERGY CONTENT DF DIETS (KCal/Ka) Trial \#2

$\begin{array}{cccc}\text { gm/kg grams } & \text { energy/ } & \text { total } \\ \text { of diet available } & \text { gram } & \text { energy } \\ \text { fed } & \text { tofish } & (k c a l) & \text { obtained (Koal }\end{array}$

High Fat Diet

$\begin{array}{lllll}\text { protein } & 350.0 & 350.0 & 3.9 & 1365.0 \\ \text { fat } & 241.1 & 241.1 & 9.0 & 2170.0 \\ \text { total } & & & & 3535.0\end{array}$

Sucrose Diet

$\begin{array}{llllr}\text { protein } & 550.0 & 550.0 & \$ .9 & 1365.0 \\ \text { fat } & 141.1 & 141.1 & 9.0 & 1270.0 \\ \text { sucrose } & 259.2 & 219.5 * & 4.1 & 900.0 \\ \text { total } & & & & 55.5 .0\end{array}$

Molasses Diet
protein
$\$ 50.0$
350.0
5.9
1365.0
fat
141.1
$1.41 \times 1$
9.0
1270.0
sucrose
252.0**
$214.2 *$
4.1
878.5
total.
551.5

* = sucrose is only 85\% digestible by salmonids ** = mol asses contains about bo\% sucrose;

420 grams of molasses a 60\% sucrose = $252 \mathrm{~g}$ sucros 


\section{RESULTS}

\section{Effects of Methyl-Testosterone Ireatment}

The effects of MT treatment on experimental fish, as described in the methods and materials section, are shown in Table $V$ for fish from both feeding trials. In the first trial, $31.2 \%$ of the fish were described as sterile, $5.3,0 \%$ as underdeveloped males and $12.5 \%$ as underdeveloped females while oriy $5.5 \%$ had fully developed gonads of either sex. In the second trial the trend continued to show a pronounced effect of MT treatment on sexual development, with $10.0 \%$ of the fish considered sterile and $8.0 \%$ of the fish showing under- developed gonads. Dnly $7.0 \%$ of treated fish had fully developed gonads which were easily identified. All control fish (100\%) were fully developed in both trials and were sexed with ease. Male: female sex ratio in control fish favored the female $1: 1.5$, while in treated fish which were identified the sex ratio was $3: 1$. Total effects of treatment (Table $V$ ) are shown graphically in Figure 1. Dverall, $20.6 \%$ of treated fish were judged to be sterile, $45.2 \%$ underdeveloped males, $27.9 \%$

underdeveloped females, $4.8 \%$ developed males and $1.6 \%$ developed females. Histological examination of treated (35\#) and control (15\#) fish gonads from fish of the same spawning group as those used in both trials gave results 
Table V - The Effect of Treatment With 17a-methyltestosterone on the Sexual Development of fiainbow Trout (numbers given are \% of total number of fish)

** Sterile Undev-M Undev-F Full M/F M:F Fatio

Trial \#1

Treat

Contr

$31.2 \%$

$53.0 \%$

$12.3 \%$

$3.5 \%$

$5: 1$

ial \#2

Treat

Contr

$10.0 \%$

$38.4 \%$

$44.7 \%$

$100.0 \%$

$1: 2.2$

Total

\begin{tabular}{|c|c|c|c|c|}
\hline $\begin{array}{l}\text { Treat } \\
\text { Contr }\end{array}$ & $20.6 \%$ & $45.7 \%$ & $28.5 \%$ & $\begin{array}{r}5.25 \% \\
100.0 \%\end{array}$ \\
\hline
\end{tabular}

\section{**}

Sterile = no evidence of gonadal material, cannot be idertified

Undev-M = underdeveloped male-testis rudimentary and difficult to identify

undev-F = underdeveloped female-egg follicle rud mentary, difficult to identify

Full MeE = fully developed male or female-sexes easily differentiated

MeF Retio = male: female ratio 
Figure 1 Dveral1 effect (Trial \#S 182) on rainbow trout sexual development of treatment with 17a-methyltestosterorie early in 1 ife (shown as a percentage of total population). STERILE = no gonadal material present: cannot be identified grossly.

LU = underdeveloped inale or female: difficult to identify.

FD = fully developed male or female: easily identified. 

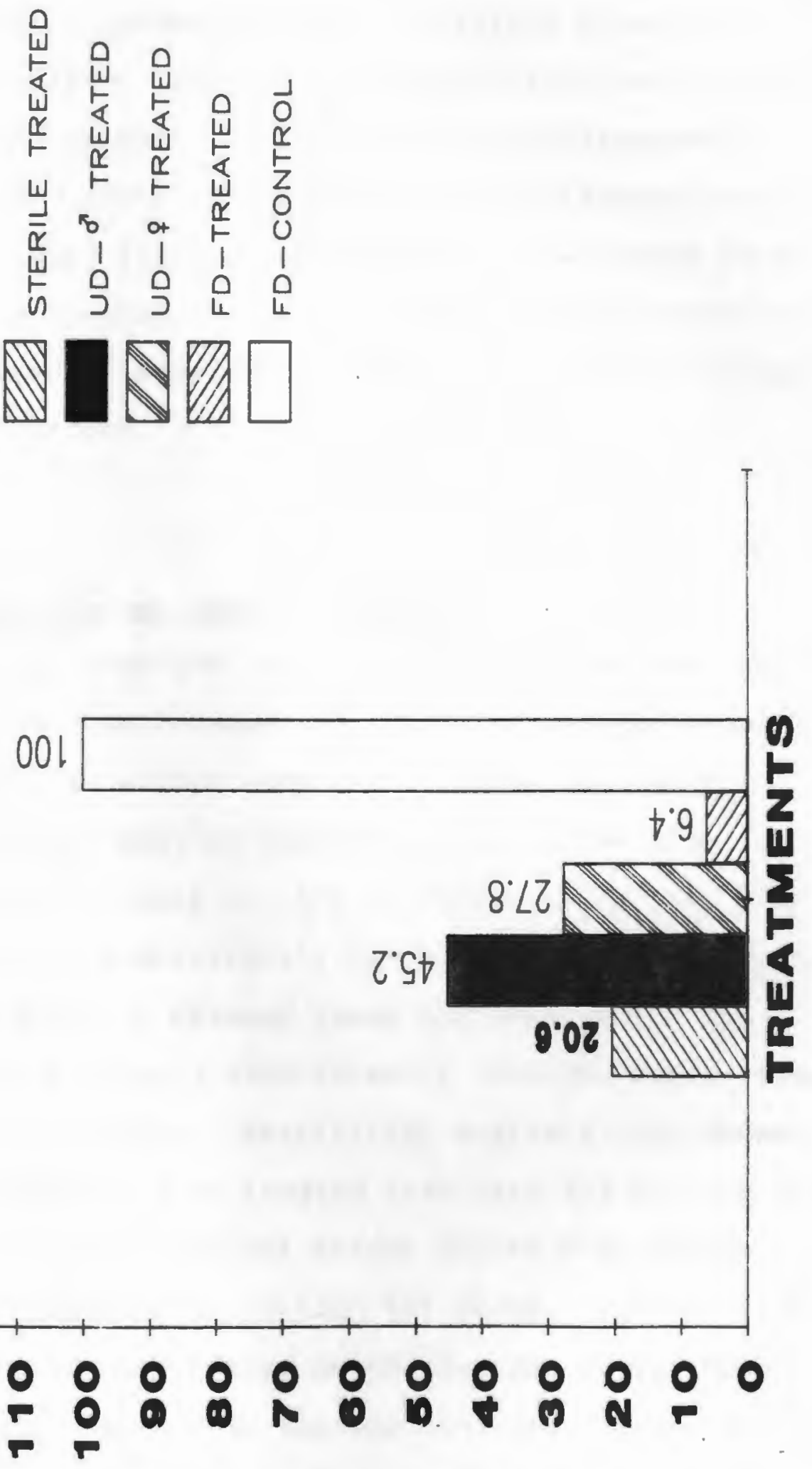
which generally agreed with thos obtained from gross visual inspection. All treated rainbow trout which were examined were at only initial stages of development or contained only connective tissue and/or primordial germ cells. The only fully-developed, functional males were found in the control fish which were examined. Females at several stages of development were found in both treated and control groups.

\section{Irial I--Sucrose vs. High Fat Diets}

Actual mean weight gain, mean length gain and feed, conversion were calculated for each diet and for treated and control fish within each diet. These are shown in Table VI and increase in mean weight gain over time is demonstrated in Figure 2. The difference in weight gain was found to be significantly different between feeds and for the interaction between feeds and treatment. The sucrose diet had gains significantly $(P<0.05)$ better than did the high fat diet. Statistical analysis also showed that the interaction of treated fish with the sucrose diet gave significantly $(P<0.05)$ better growth than either control or treated fish on high fat diets. Treated fish showed improved performance on the sucrose diet, though not significantly better than sucrose controls. Overall, the treatment alone had no significant effect on growth at 
Table VI - Mean growth parameters for treated and control rainbow trout after feeding for 12 weelss with high-fat and sucrose diets Trial \#1

$\begin{array}{clccc}\text { initial wt/ actual relative } & \text { actual } & \text { feed } \\ \text { final wt } & \text { gain } & \text { gain } & \text { length } & \text { conversion } \\ \text { (grams) } & \text { (grams) } & & \text { gain(cm) } & \text { (protein) }\end{array}$

$\begin{array}{lrllll}\text { Hiqh-Fat Diet } & & & & \\ \text { Treated } & 17.2 / & & & & \\ & 77.6 & 60.4+ & 3.51+ & 7.03 & (26.7 \%) \\ \text { Contral } & 19.8 / & & & \\ & 90.6 & 70.7+ & 3.56+ & 7.57 & (31.2 \%) \\ \text { Total } & 18.6 / & & & & 1.39 * \\ (\text { mean) } & 84.4 & 65.8 * & 3.54 & 7.30 * & (29.0 \%)\end{array}$

Sucrose Diet

\begin{tabular}{|c|c|c|c|c|c|}
\hline Treated & $\begin{array}{l}20.5 / \\
102.5\end{array}$ & $82.0+$ & $4.01+$ & 8.02 & $\begin{array}{c}1.24++ \\
(32.3 \%)\end{array}$ \\
\hline Control & $\begin{array}{l}22.41 \\
100.5 \\
\end{array}$ & 78.2 & $3.51+$ & 7.97 & $\begin{array}{r}1.28++ \\
(31.3 \%)\end{array}$ \\
\hline $\begin{array}{l}\text { Total } \\
\text { (mean) }\end{array}$ & $\begin{array}{l}21.4 / \\
101.5\end{array}$ & $80.1 *$ & 3.74 & $8.00 *$ & $\begin{array}{l}1.26 * \\
(31.8 \%)\end{array}$ \\
\hline
\end{tabular}

1 = relative gain = gain (grams) / initial weight (grams)

- = protein conversion = \% protein efficiency

* = fish fed sucrose diet had significantly better (F<0.05) actual weight gain, length gain and feed conversion than did those fed high-fat diet

$+=$ treated $f i s h$ on the sucrose diet had significantly improved (F<0.05) actual weight gain over treated and contral fish fed the high-fat diet; sucrose fed treated fish had significantly improved (F<0.05) relative weight gain over all other groups

$++\Rightarrow$ treated fish fed the high-fat diet had the poorest feed conversion: the remaining groups were not significantly different ( $P<0.05)$ 
Figure 2 Actual gain (grams) of treated and control rainbow trout fed high-fat and sucrose diets for 12 weeks. Trial \#1. 


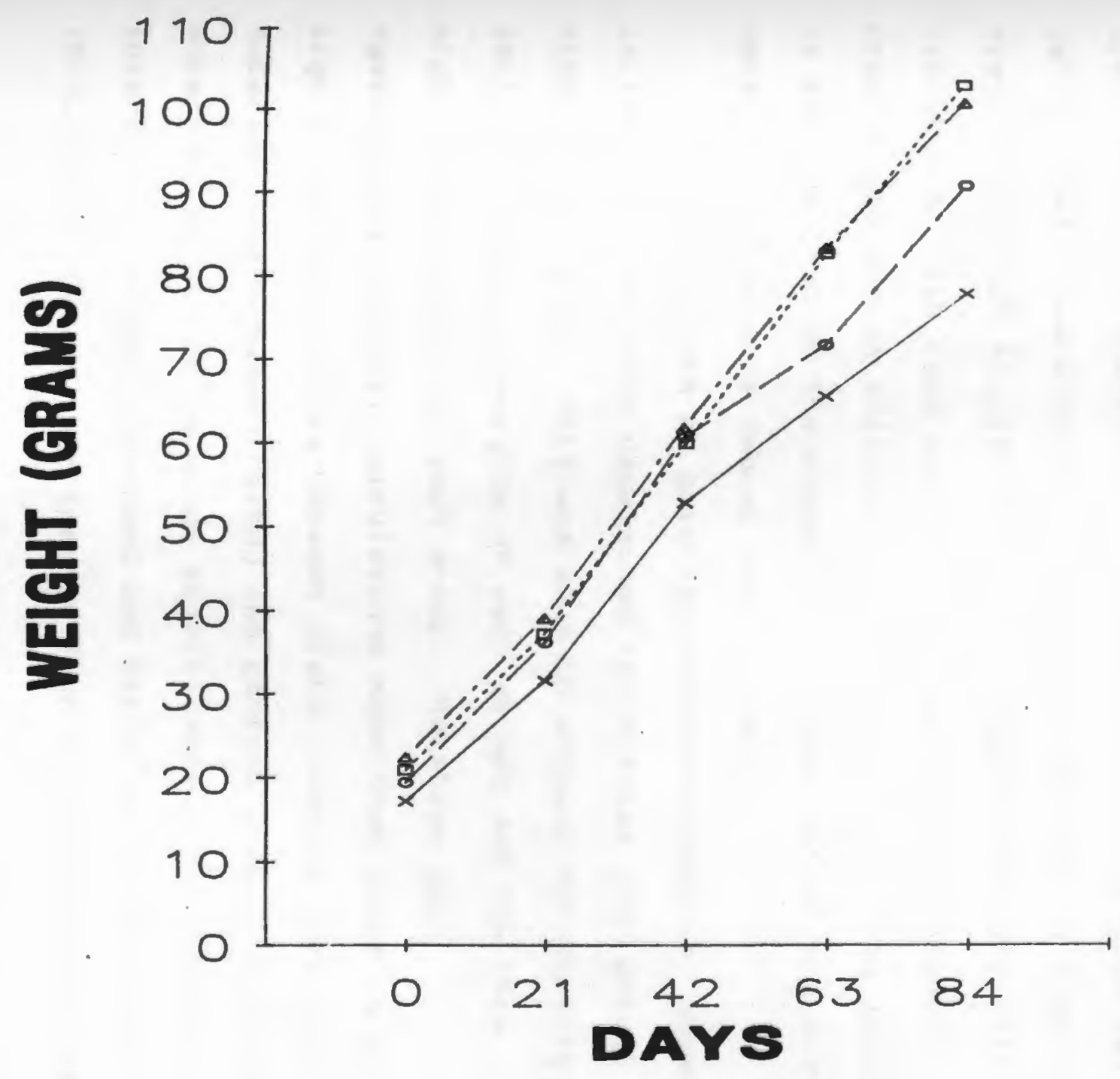

$\times$ FAt/TREATEd

- FAT/CONTROL

- SUCROSE/TREATED

$\triangle \quad$ SUCROSE/CONTROL 
$P<0.05$. There was a significant difference $(P<0.05)$ in mean length gain only between the two diets, with the sucrose diet giving better 1 inear growth. The feed conversion data shown in Table VI demonstrates that fish on the sucrose diet had significantly improved (F<0.05) overall feed conversions than those fed the high fat diet. An interaction effect is also in evidence, with treated fish doing better on the sugar diet than on the high fat diet ( $P(0.05)$. Treated fish fed the sugar diet also had better feed conversions than control fish fed the sugar diet, though not significantly so. Figure 3 graphically illustrates mean feed conversion values for all groups. Frotein conversion efficiencies were naturally also better in treated fish on the sugar diet because all of the diets were iso-nitrogenous (equal protein levels).

Relative growth or gain (gain/initial weight), shown in Table VI, was also determined for treated and control fish on each diet. This was done to account for varying initial (starting) weights of each animal and how this might affect growth in each group. Relative gain (gain/initial weight) calculations show that there were significant differences between diets (sucrose diet was superior) and between treated and control fish (treated was superior) at $P<0.05$ level of significance. The effect of interaction between treatment and diets was significant (F<0.05) and showed that treated fish on the sucrose diet 
Figure 3 Feed conversion (g. fed/g. gained) and protein conversion (\%) of treated and control rainbow trout fed high-fat and sucrose diets for 12 weet:s. Trial \#1. 


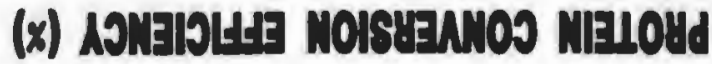

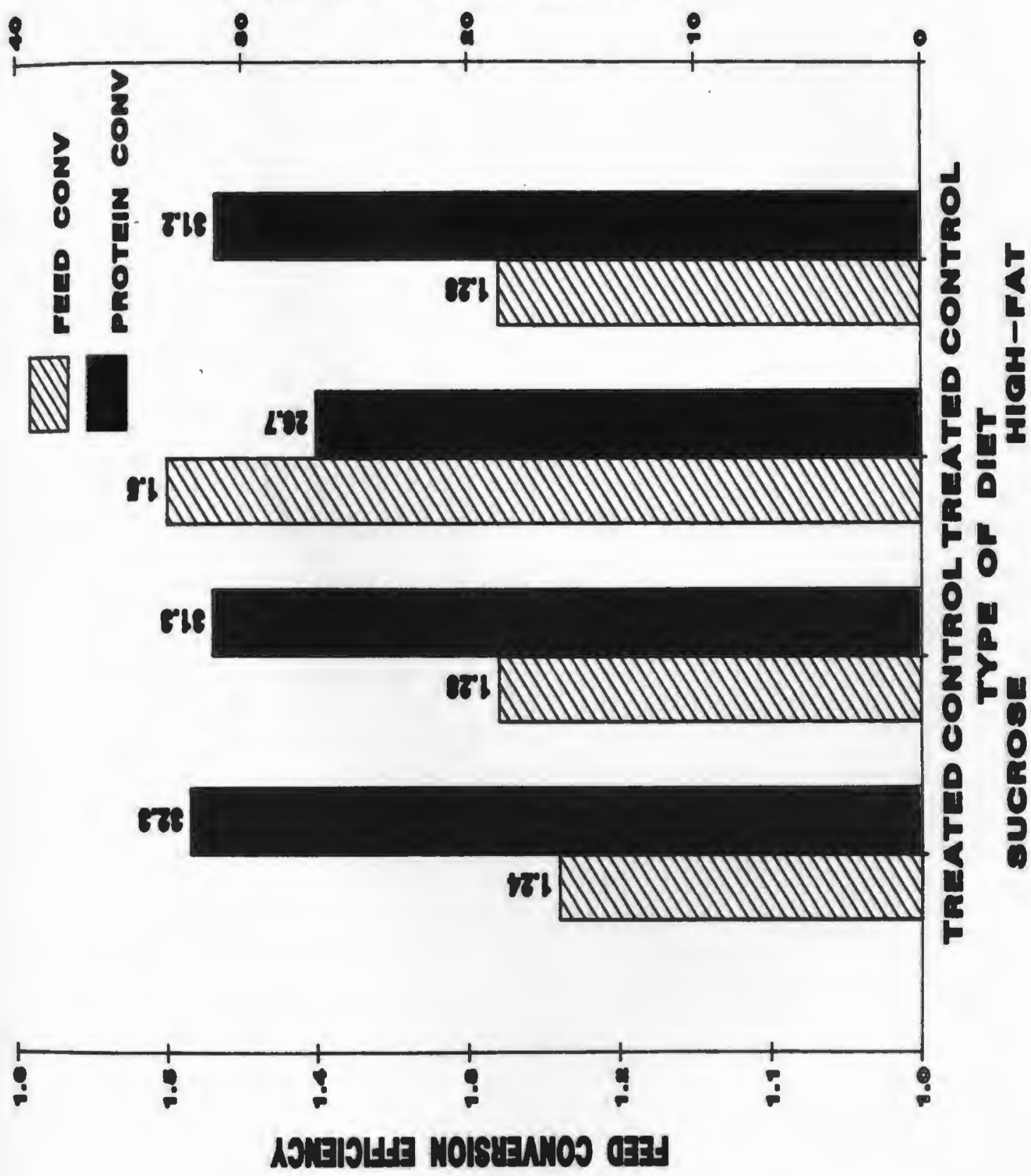


Figure 4 Felative gain (gain/initial wt) of treated and control rainbow trout fed high-fat and sucrose diets for 12 weeks. Trial \#1. 


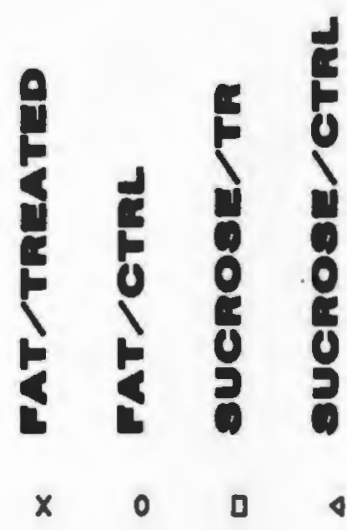

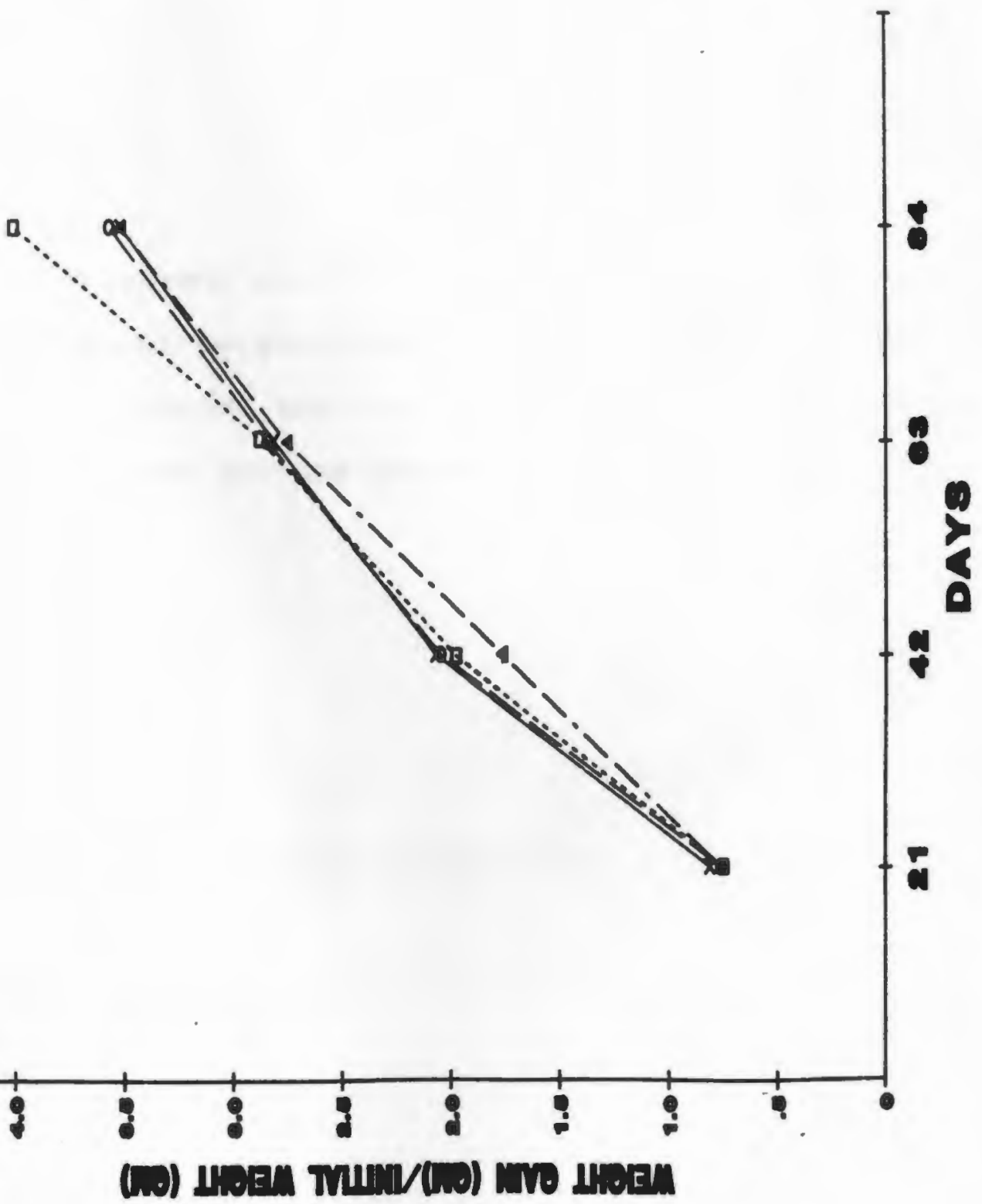


Figure 5 Treatment and feeds interaction effect on actual weight gain and feed conversion levels in treated and control rainbow trout fed highfat and sucrose diets for 12 weeks. Trial \#1. 


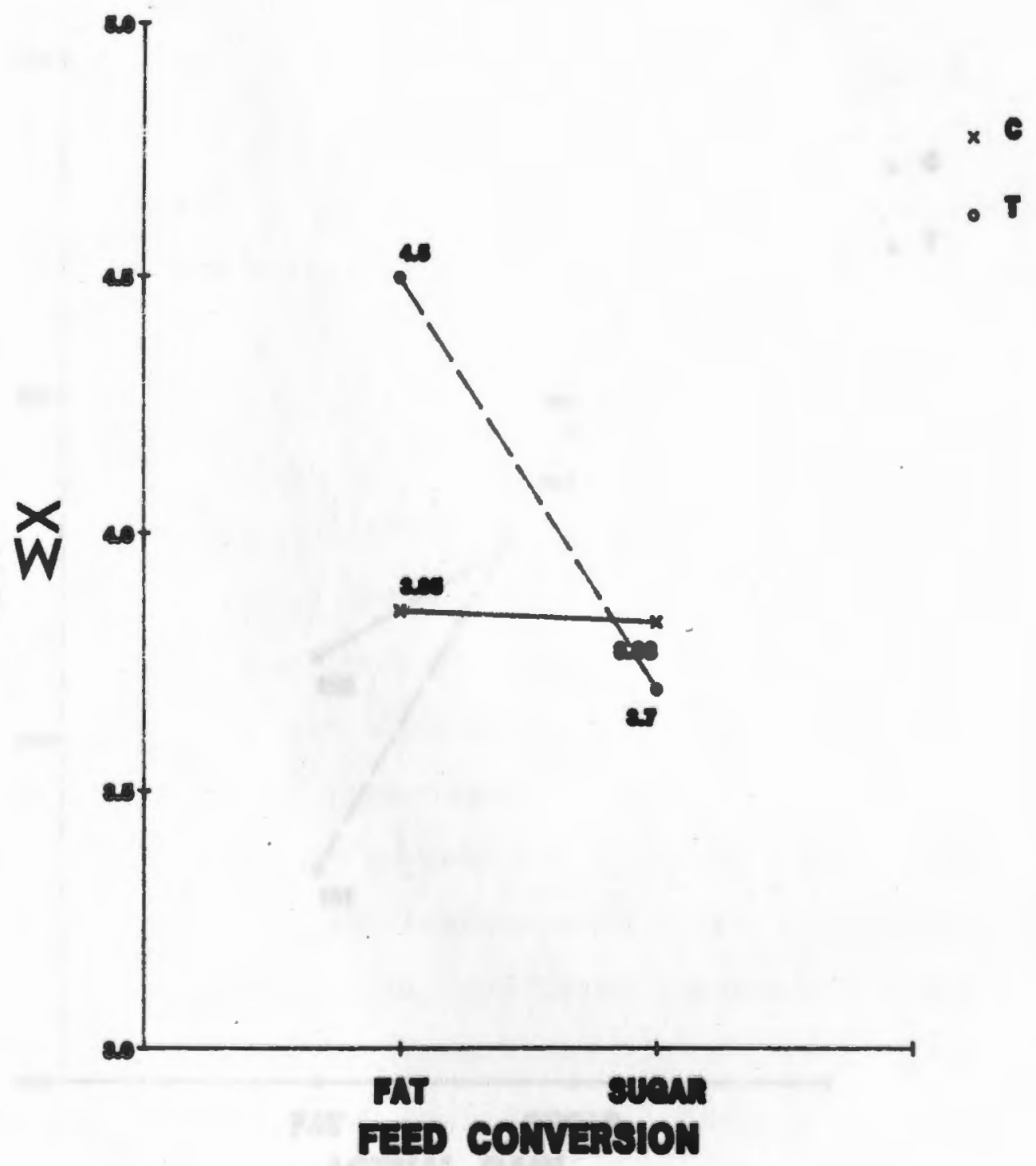




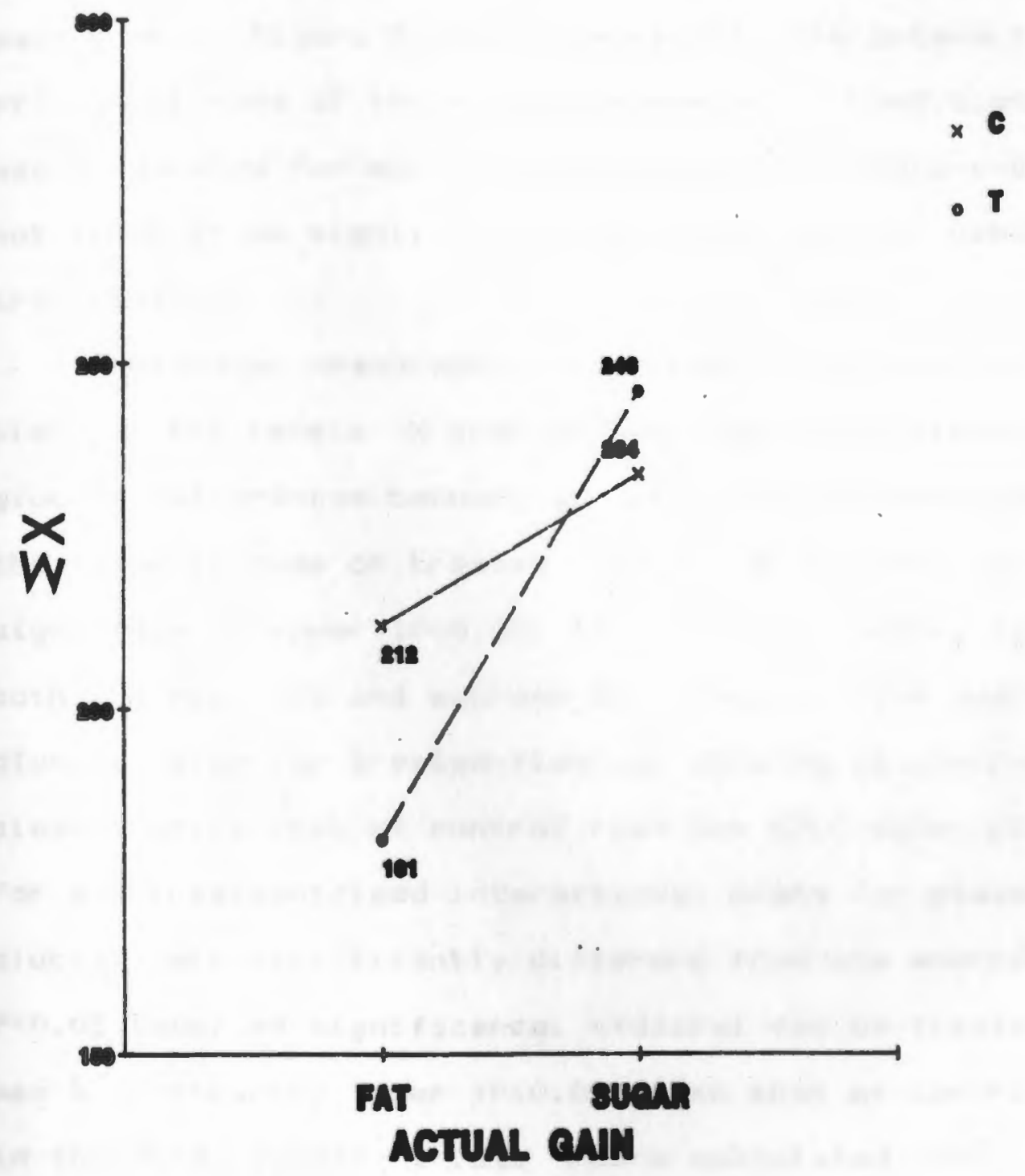


grew better (taking into account initial size) than did treated fish on the high fat diet. Treated/sucrose fish also gained better than control fish on both sugar and high fat diets. Figure 4 shows relative growth over time for each group. Figure 5 shows graphically the interaction effects of some of the growth parameters. Condition factor was calculated for each group based on mean data and was not found to be significantly different between diets or treatments.

Individual measurements were used in determining visceral fat levels (\% body weight) and blood plasma glucase differences between groups. Fiesults indicated that the blood glucose of treated fish at termination was significantly lower (P60.05) than that of control fish in both the high fat and sucrase diet groups. The mean blood glucose value for treated fish was $65.6 \mathrm{mg}$ glucose/ml plasma, while that of control fish was $82.7 \mathrm{mg} / \mathrm{ml} \mathrm{plasma}$. For all treatment/feed interactions, means for plasma glucose were significantly different from one another at F<0.05 level of significance. visceral fat of treated fish was significantly lower (P<O. OS) than that of control fish in the first feeding trial. Means calculated from individual measurements of fish visceral fat showed that treated fish had a lower visceral fat weight:body weight ratio (0.012: 1 or 1.2\% of body weight) than did control fish (0.017:1 or 1.7\% of body weight). There was no 
significant difference (up to $P(0.10)$ between visceral fat levels (\%) of fish fed sugar and high fat diets. With respect to interaction effects, using mean values of visceral fat, none of the treatment/feed combinations were significantly different from one another. Mean values for blood plasma glucose and visceral fat (\% body weight) are tabulated in Table VII and illustrated graphically in Figure $b$. No correlation was found between blood plasma ammonia levels and blood plasma glucose levels or between plasma ammonia levels and treatment or diets. There was no significant difference between fish blood ammonia on different diets, treatment or any interaction thereof.

\section{Irial II-Sucrose ve Molasses vs High Fat Diets}

Actual weight gain and length gain were determined for each fish and mean values were calculated along with feed conversion for both treated and control fish on each diet. Growth data and feed conversions for the second trial were calculated after nine weeks of feeding because of poor performance of fish in four of the six experimental tanks from weels 10-12. This is due, it was believed, to a contaminant in two of the experimental diets. After nine weeks of growth, both sucrose and molasses diets gave significantly $(P<0.05)$ better weight gain that the high fat 
Table VII - Flasma glucose and visceral fat levels of treated and control rainbow trout after feeding for 12 weeks with high-fat and sucrose diets - Trial \#1

\section{(mg/100ml)}

Plasina Glucose
(\% body weight)

Viseral Fat

High Fat Diet

Treated

Contral
5.81

57.75
1. 22

1.70

Total (mean)

$55.78 *$

$1.46+$

Sucrose Diet

\section{Treated}

77.37

Control

107.69

1.18

1.66

Total (mean)

$92.54 *$

$1.42+$

Treatment

mean

$65.60 * *$

$1.20++$

Control.

mean

82. 70

1.68 
Figure 6 Flasma glucose and visceral fat levels of treated and control rainbow trout fed high-fat and sucrose diets for 12 weeks. Trial \#1. 


\section{(x) IVt Tressth}

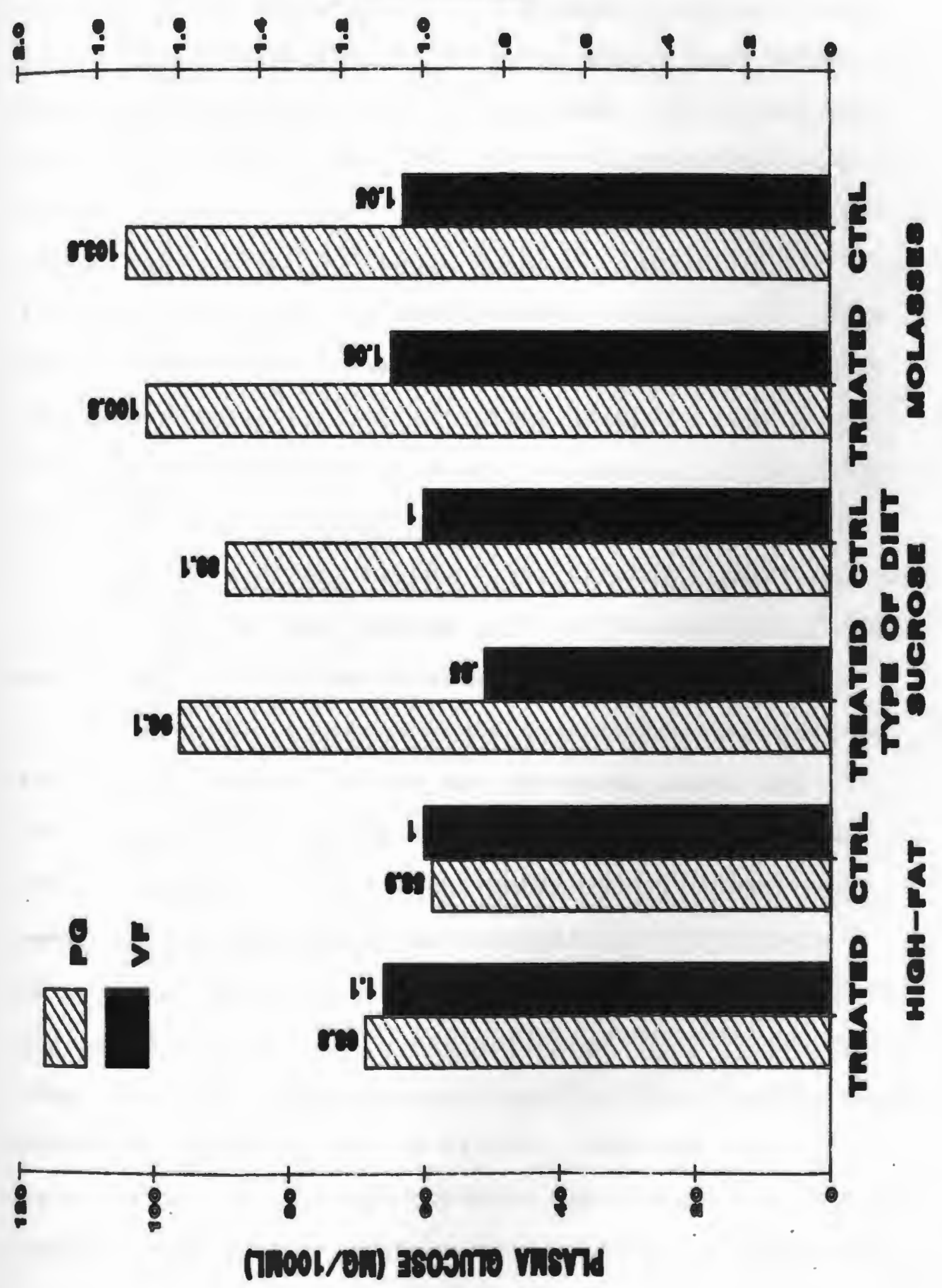


diet. Sucrose and molasses diets were not significantly different from one another with respect to actual weight gain. The treatment with MT had no significant effect on actual weight gain in any of the diets. All diets were significantly different ( $P \subset O . O 5)$ from one another with respect to mean overall length gain. But treatment had no significant effect on length gain, nor did interaction of treatment and different feeds affect length gain. Feed conversions of the molasses and sucrose diets were much better and significantly different $(P<0.05$ ) from those obtained for the high fat diet. Values for actual mean weight gain, mean length gain and feed conversions are - shown in Table VIII. Figure 7 illustrates weight gain over time for control and treated fish within each diet. Feed conversion data is represented in Figure 8 .

Mean relative gain (weight gain/initial weight) for treated and control groups fed the three diets was calculated in the second trial by averaging individual relative gains for each fish (Table VIII). After nine weeks of feeding, there was a significant difference $(P<0.05)$ in relative growth between both feeds and treated versus control groups. Interaction of the two variables (feed and treatment) was also found to have a significant effect on relative gain at $P<0.01$. The diet high in fat gave the poorest average relative gain (ave=1.16), while the molasses diet gave the best results (ave=1.53). The 
sucrose diet (ave=1.44) did not do as well as the molasses diet but showed a significantly better response than the high fat diet. The molasses diet fish had significantly better ( $\mathrm{PCO}$. OS) relative growth than either of the other two diets. Mean separation tests (LSD) showed that treated $f i s h$ fed the molasses diet had better relative growth than any of the other interaction means. Treated fish on the sucrose diet had significantly better relative growth than treated fish on a high fat diet, as was the case with contral/sucrose versus control/ high fat fish. Overall, treated $f$ ish on a diet high in digestible CHOs exhibited better relative gains than any other group (Table VIII). Figure 9 illustrates the effect of relative growth over time for treated and control fish on each diet. Interaction effects of some growth parameters are shown in Figure 10. Calculation of fish condition factor yielded no significant differences between diets or treatments.

Mean values for blood plasma glucose and visceral fat levels (\% body weight) were determined for both treated and control fish fed each diet. Statistical analysis of mean plasma glucose levels showed that there was a significant difference between the different feeds ( $F<0.05$ ) and mean separation tests (LSD) showed that both the sucrose and molasses diets were significantly higher in glucose than the high fat diet. The sucrose and mol asses diets were not significantly different from one another in plasma glucose 
Table VIII - Mean growth parameters for treated and control rainbow trout after feeding for 9 weelss with high-fat, sucrose and molasses diets - Trial \#2

$\begin{array}{ccccc}\text { initial wt/ actual } & \text { relative actual } & \text { feed } \\ \text { final wt } & \text { gain } & \text { gainz } & \text { length } & \text { conversion } \\ \text { (grams) } & \text { (grams) } & & \text { gain(cm) } & \text { (protein) }\end{array}$

Hiah Fat Diet

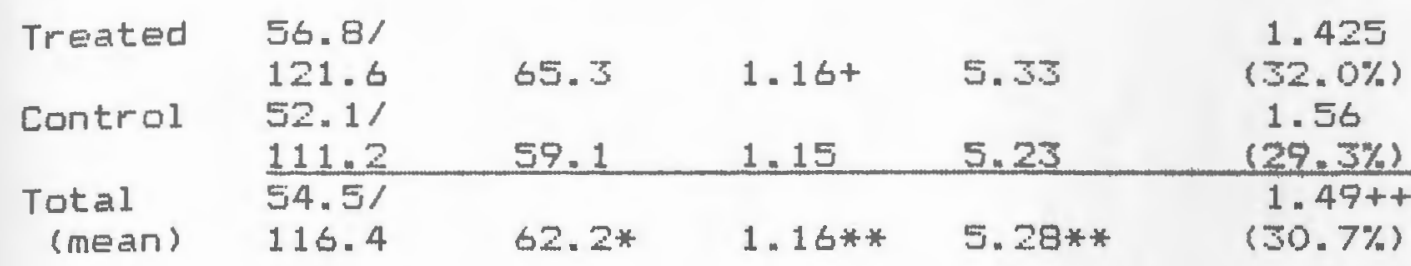

Sucrose Diet

Treated $57.6 /$

1.39 .9

Control 55.1/

$82.3 \quad 1.44+\quad 5.85$

1.17

$\begin{array}{cc}\text { Total } & 13.3 .0 \\ \text { (mean) } & 13.36 .6\end{array}$

7

5.95

$(39.0 \%)$

1. 23

$(37.2 \%)$

$80.3 *$

1.44

1. $20++$

(38.1\%)

Molasses Diet

Treated $52.5 /$

$\begin{array}{cccccc}\text { Control } & \begin{array}{c}134.0 \\ 56.97\end{array} & 81.55 & 1.61+ & 6.22 & (38.0 \%) \\ & 138.4 & 81.51 & 1.45 & 5.85 & 1.13 \\ \text { Total } & \frac{134.7 /}{54.7 \%} & & & & (3.2 \%) \\ \text { (mean) } & 136.2 & 81.53 * & 1.53 * & 0.04 * * & (3.183++\end{array}$

1.19

$38.0 \%)$

$(37.2 \%)$

$(37.6 \%)$

\footnotetext{
1 = final weight at 9 weeks

$z=$ relative gain = gain (grams)/initial weight (grams)

$=$ protein conversion = \% protein efficiency

* = sucrose and molasses diets gained significantly better (FC0.05) than did the high-fat diet

* = all diets were significantly different (F<0.05) from the other two diets in length gain and relative weight gain (molasses and sucrose were superior)

$+=$ treated fish fed molasses showed significantly improved relative gain over all'other groups; sucrose? high-fat $++=$ molasses and sucrose diets gave significantly better (F>0.05) feed conversions than the high-fat diet
} 
Figure 7 Actual gain (grams) of treated and control rainbow trout fed high-fat, sucrose and molasses diets for 9 weeks. Trial \#2. 


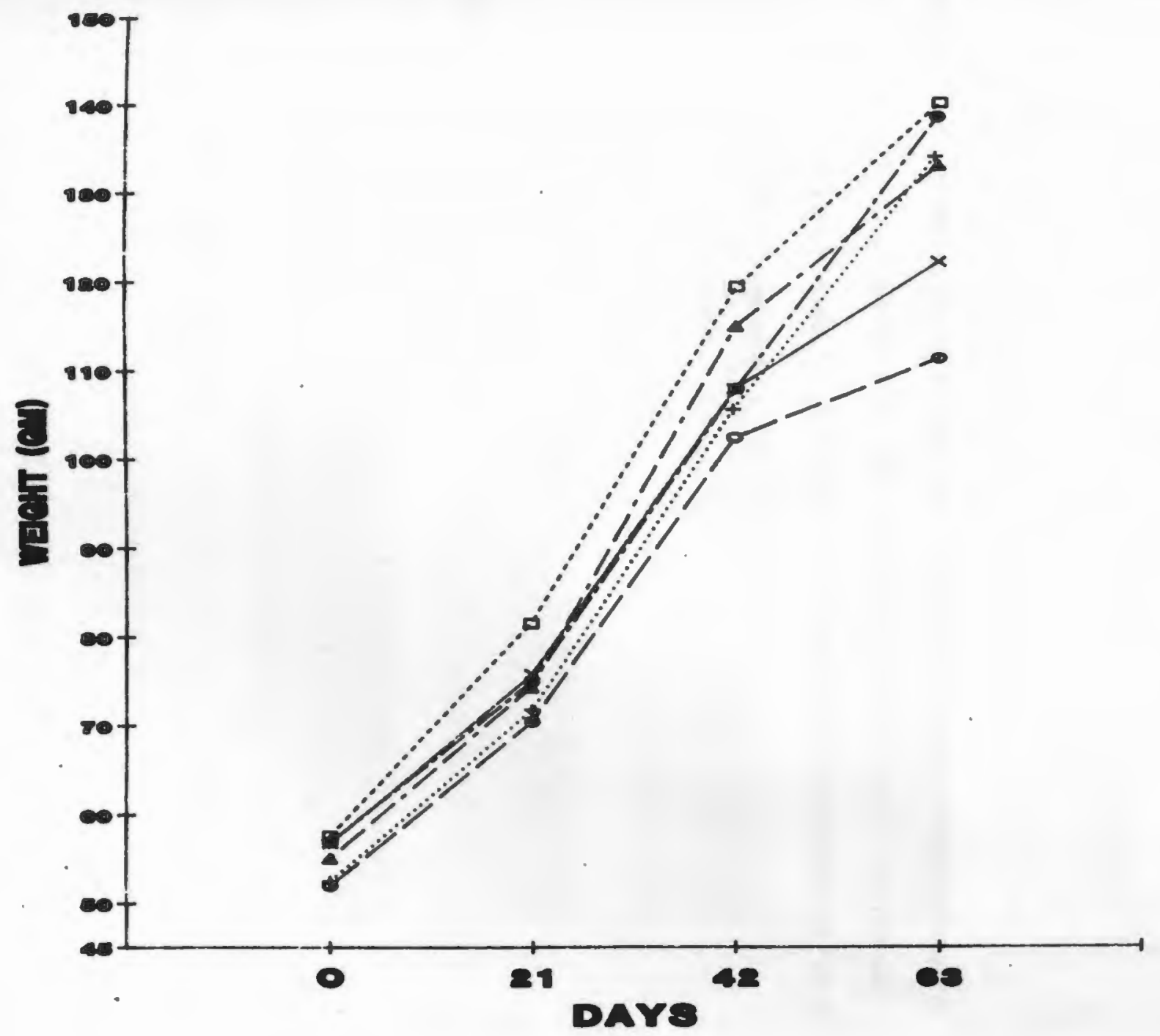

$\times$ FAT/TREATED

- FAT/CTRL

- SUCROSE/TR

- SUCROSE/CTRL

+ Molasses/Tr

- molasses/CTRl 
Figure 8 Feed conversion (g. fed/g. gained) and protein conversion (\%) of treated and control rainbow trout fed high-fat, sucrose and molasses diets for 9 weel:s. Trial \#2. 


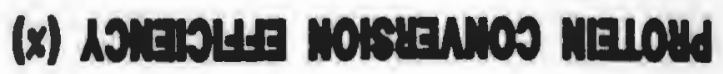
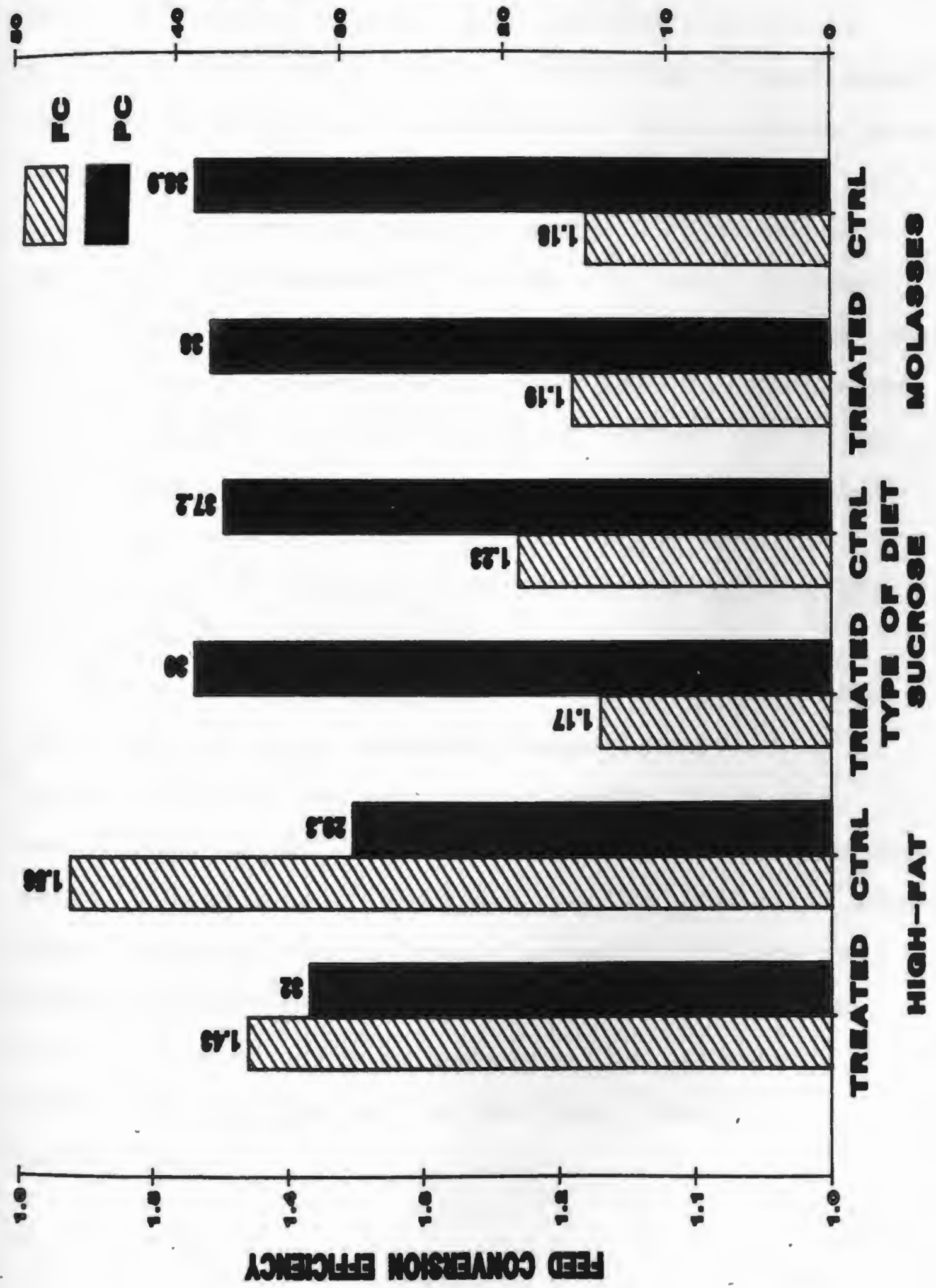
values. Blood plasma glucose values of treated fish were not significantly different from those of control fish. Measurement of visceral fat as a percentage of body weight resulted in significant differences ( $P$ ( 0.05 ) between feeds with only the sucrose diet being significantly lower in \% visceral fat than the other two diets. There were no significant differences in visceral fat levels between treated and control groups, but treated fish did have lower mean levels of visceral fat $(1.021 \%$ than did non-treated fish (1.0286\%). Average results for visceral fat \% and blood plasma glucose levels are shown in Table IX and in Figure 11. Ammonia levels in blood plasma showed no correlation with any other factors, with no significant differences in levels between treatment or diets.

In a related feeding study, using three commercial pelleted diets which contained varied levels of carbohydrate, treated and control rainbow trout were individually marled using a freeze-branding technique and fed for 12 weetss under stringent controls (Smith and Ahern, 1985). Fiesults from the study, agreeing with some of those obtained from this thesis research, showed that treated fish outperformed controls in all parameters measured and did the best on the diets highest in carbohydrates. 
Table IX - Flasma glucose and visceral fat levels of treated and control rainbow trout after feeding for 9 weelss with high-fat, sucrose and molasses diets - Trial \#2

\section{( $m g / 100 m 1$ ) \\ Flasma Glucose \\ (\% body weight) \\ Visceral Fat}

High Fat Diet

Treated

68. 78

1.13

Control

58.95

1.0 .5

Total (mean) $63.87 * \quad 1.08+$

Sucrose Diet

Treated

96.07

0.85

Control

89.10

1.01

Total (mean)

$92.59 *$

$0.93+$

Molasses Diet

Treated

Control

100.79

1.08

103.82

1.05

Total (mean)

$102.30 *$

$1.07+$

Treatment

mean

88. $55 * *$

$1.02++$

Control

mean

8.5. $96 * *$

$1.0 .3++$

\footnotetext{
* = plasma glucose significantly lower (F<0.05) for high fat diet as compared to other two diets

* = plasma glucose is not significantly different (PCO.05) between treatments

$+=$ visceral fat is significantly lower (P<0.05) for sucrose diet as compared to other two diets

$++=$ visceral fat is not significantly different (F<0.05) between treatments
} 
Figure 9 Felative gain (gain/initial wt) of treated and control rainbow trout fed high-fat, sucrose and molasses diets for 9 weeks. Trial \#2. 


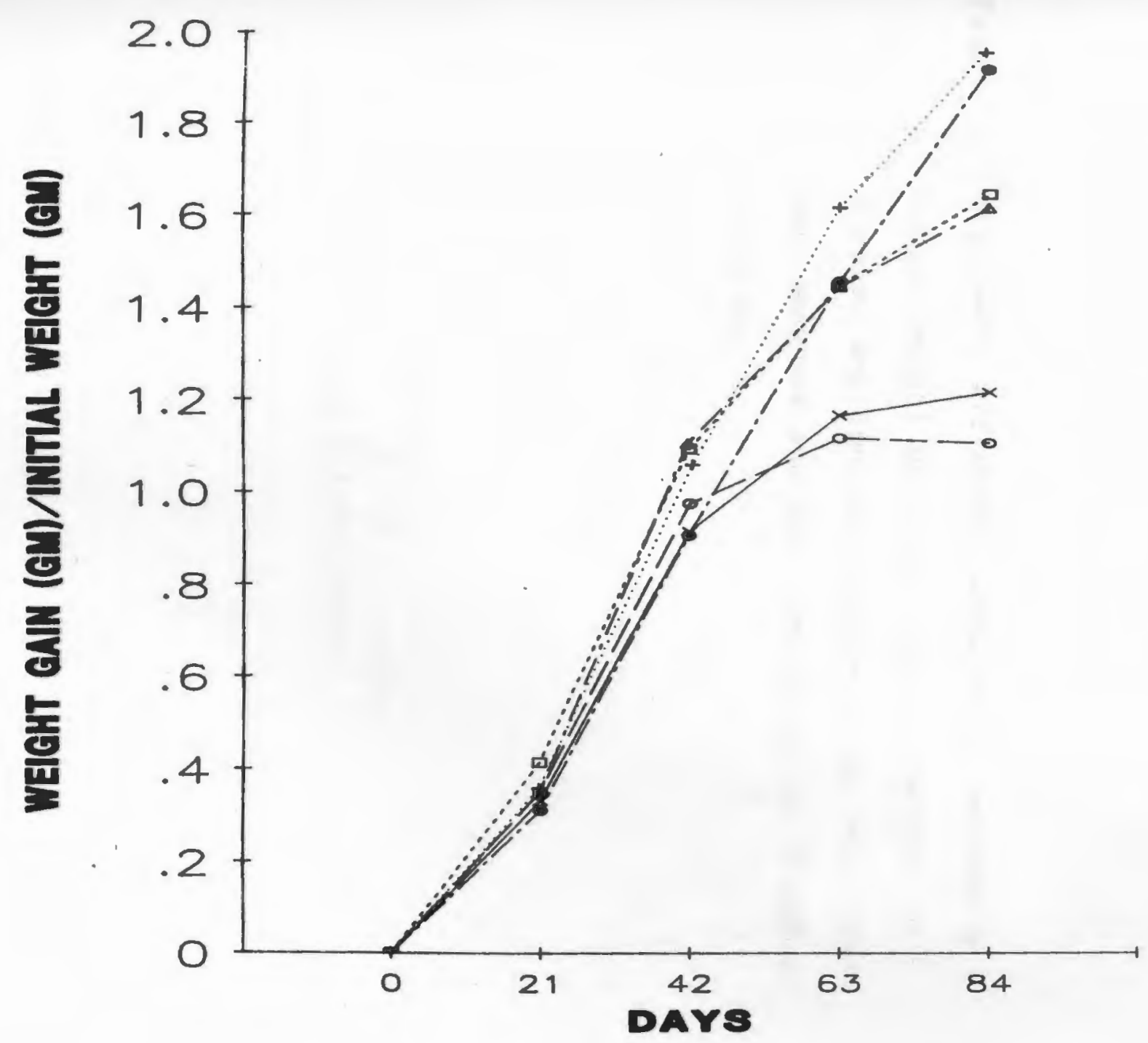

$\times$ FAT/TREATED

- FAT/CTRL

- SUCROSE/TR

$\triangle$ SUCRÓSE/CTRL

+ Molasses/Tr

- molasses/Ctrl 
Figure 10 Treatment and feeds interaction effect on actual weight gain and feed conversion in treated and control rainbow trout fed highfat, sucrose and molasses diets for 9 weeks. Trial \#2. 


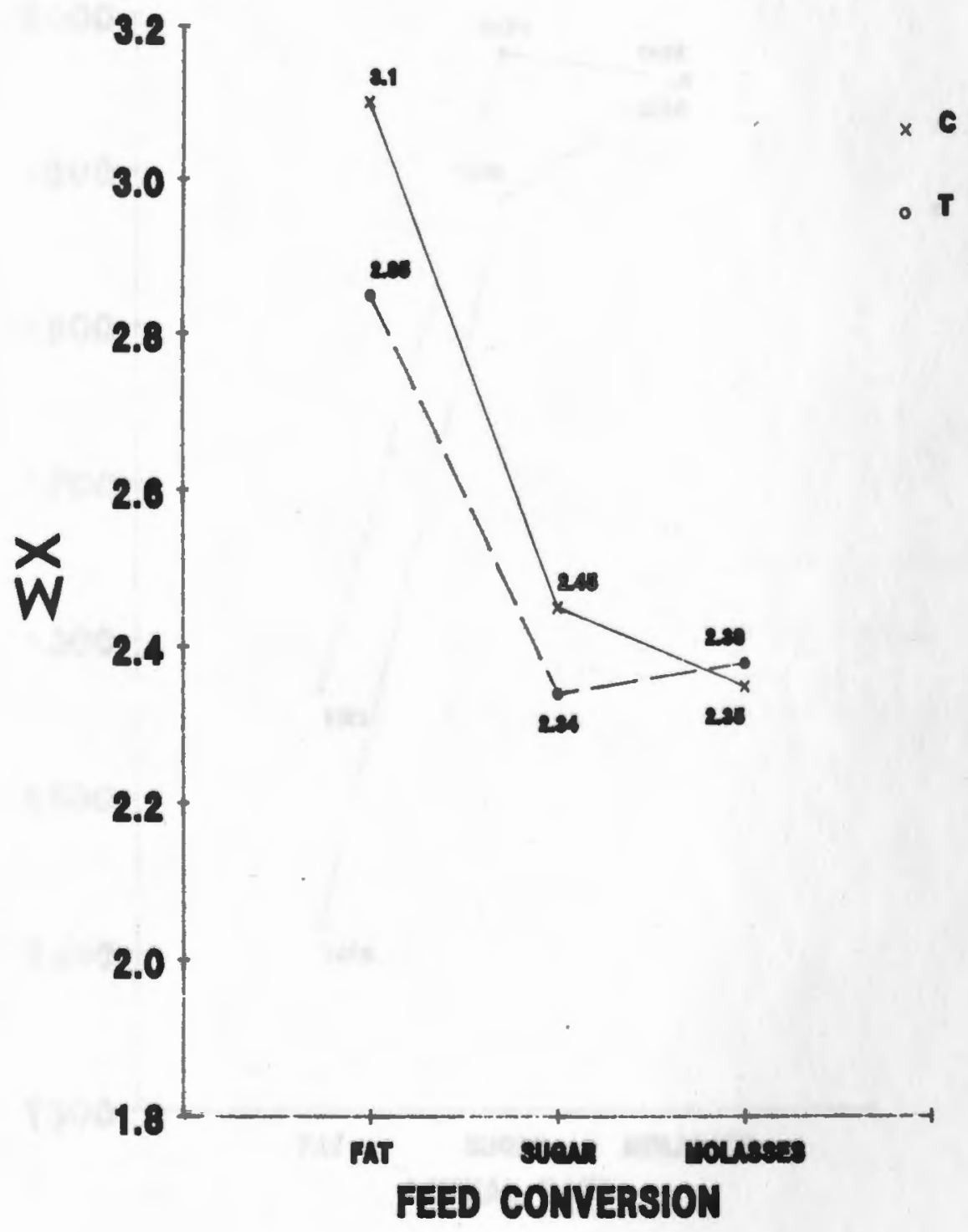




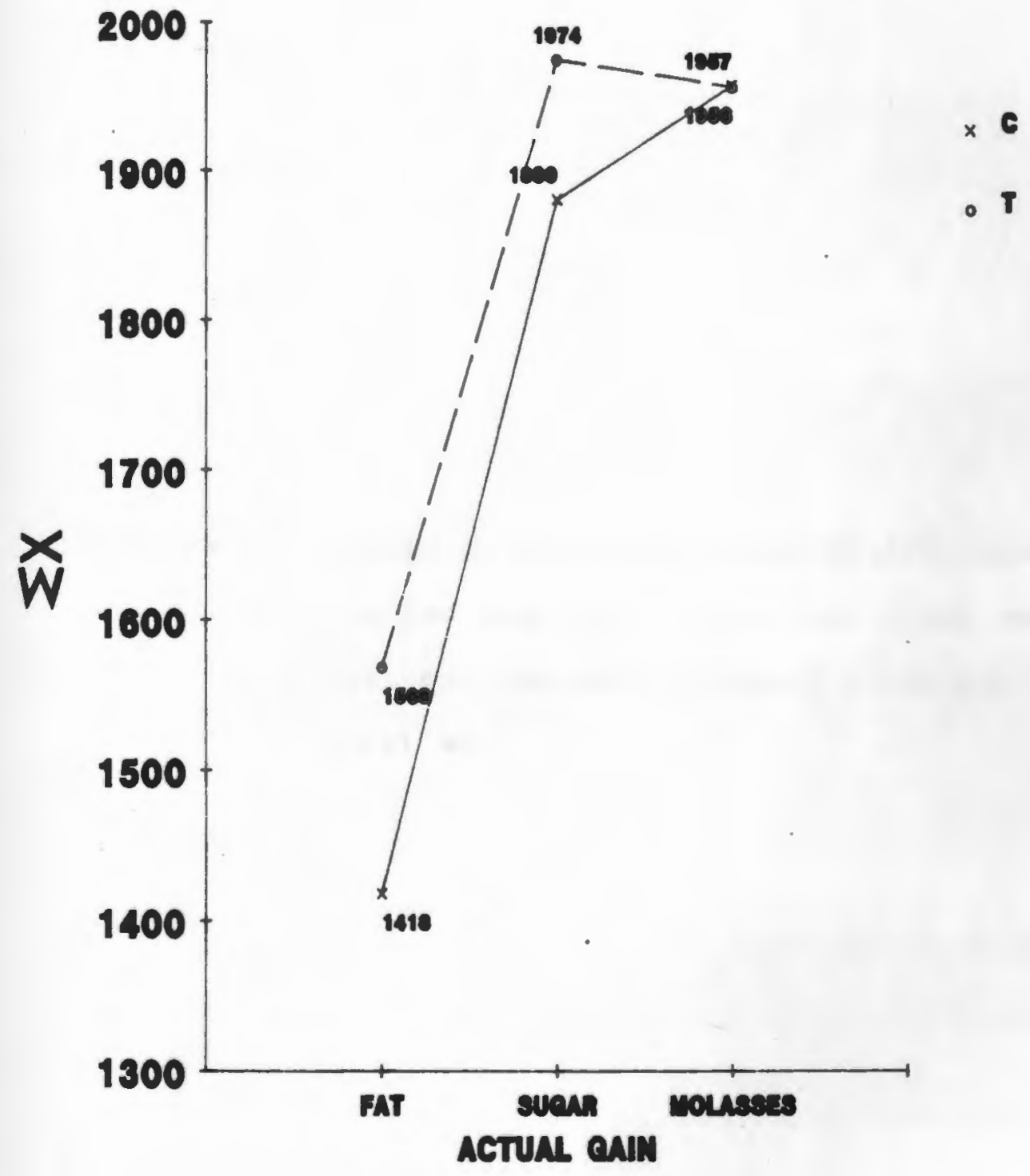


Figure 11 Fiasma glicose and visceral fat levels of treated and control rainbow trout fed highfat, sucrose and molasses diets for 9 weeks. $\operatorname{Tri} 21$ \#2. 
(x) LVA Treosu
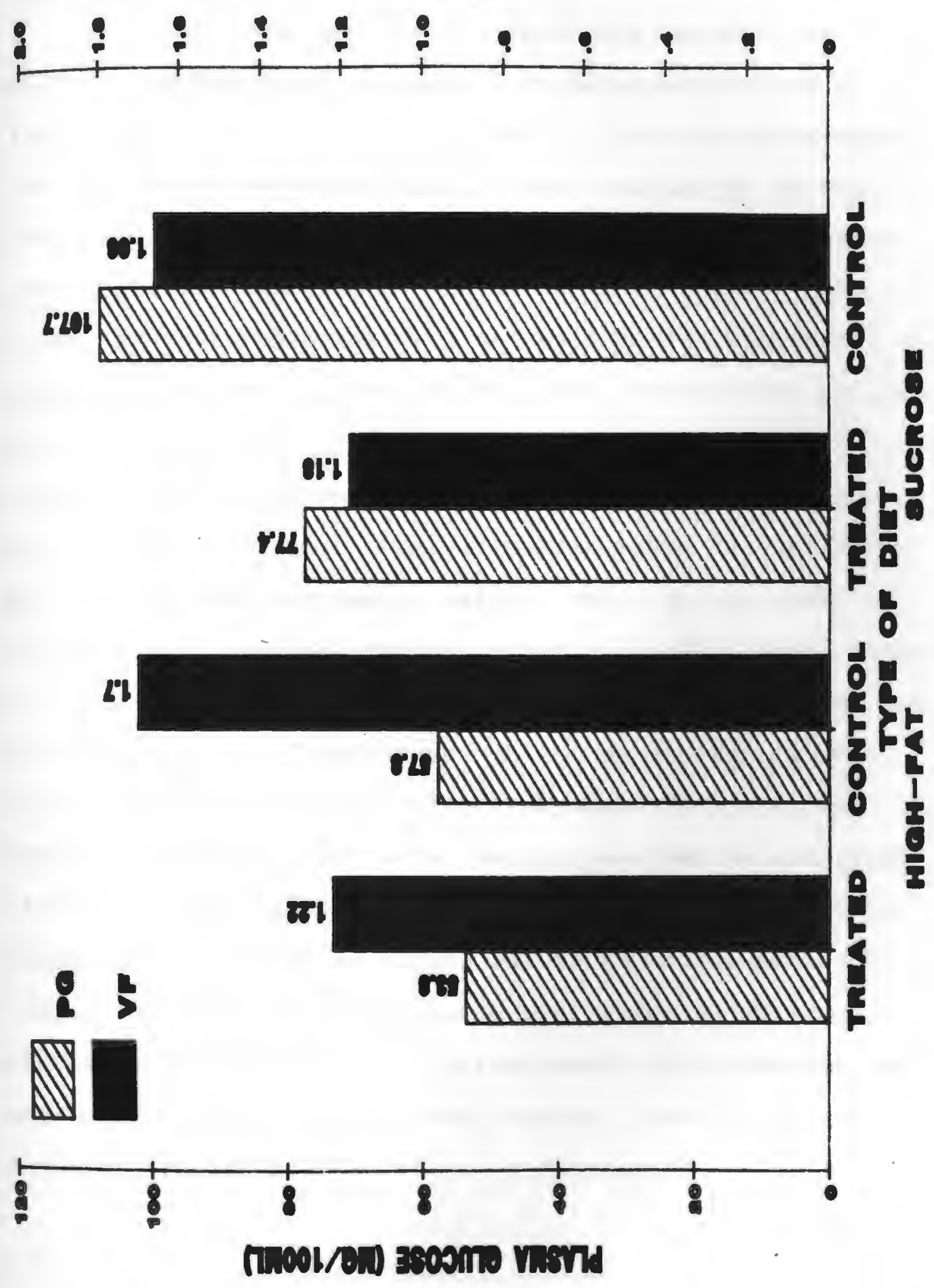


\section{Eeed Formulation Results}

All feeds were produced by identical methodology (see Methods and Materials section). Fhysical properties of all feed pellets were adequate for use in fish culture systems. The sucrose and molasses diets showed the better physical characteristics, dropping slowly through the water coluin and eventually settling on the bottom of the tank. All diets were palatable to the fish, as they fed vigorously at feeding time, eating even pellets which had settled to the bottom of the tank. The high fat diet was the least desirable of the three diets, with a portion often floating on the water surface. Observation indicated that this portion was also eventually eaten. The high fat diet produced the greatest amount of physical solids waste while the sucrose diet produced the least. The molasses diet was intermediate in solids production and produced a water discoloration immediately after feeding. This cleared though, within $1 / 2$ hour after feeding and had no noticeable affect on performance of the diet. Solid waste production seemed directly related to the amount of undigestible CHO (filler) in the diet; a diet with no filler produced no waste. Proper addition of anti-oxidants and preservatives extended the shelf Iife of each product (feed) over the duration of each experiment. 


\section{DISCUSSION}

Administration of alpha-methlytestosterone at a dose of $50.0 \mathrm{mg} / \mathrm{kg}$ of diet at the onset of feeding to rainbow trout appears to produce the desired result of sexual sterility to these fish. Almost one year after removal of MT from the diet of the fish, gross (and histological) Examination of gonads revealed that the great majority $(66.3 \%$,$) of treated fish were considered either sterile or$ underdeveloped (and non-functional) males. Gonads seen in the majority of treated fish were much less developed than those of contrals. The sex ratio of thase fish positively identified male or female heavily favored the male (3:1Table $V)$. Other investigators have obtained comparable results in various Salmo species (Jalabert et al., 1975; Johnstone et al., 1979: Harbin et al., 1980; Donaldson and Hunter, 1982; Schreck and Li, 1993). Control fish, on the other hand, were $100 \%$ identifiable as males or females and had a more balanced sex ratio $(1: 1.5)$ as compared to treated fish, and favored the female. This may indicate sex reversal from female to male when complete sterility did not occur with MT treatment. Also in agreement with previous research (Higgs et al., 1982; Rao et al., 1983; Smith, 1983), it appeared that overall, treated fish performed better in both feeding studies as compared to 
controls, long after elimination of MT from the diet. In a more detailed study on the long term effects of MT treatment in fishy, it is suggested that other measurements might be made, such as circulating serum testosterone and plasma gonadotropin (Gth) levels and calculation of gonadosomatic index differences between treated and control groups (Billard et al., 1981; Sundararaj et a1., 1982). These perameters of sexual reproductive potential would give a good indication of how well the MT treatment worked. In a study related to the feeding trials of the present study using three comercial pelleted diets fed to treated and contral fish, results indicated the superiority of treated fish over controls for all growth measurements. The use of glucose, sucrose and more complex CHOs in salmonid diets has given mixed results. Investigators have demonstrated that more complex CHOs such as starch are poorly digested by salmonids (Edwards et al., 1977:

Spannhof and Flantikow, 1983), resulting in poor growth and feed conversion. Dther researchers though, have shown that restriction of intake and gelatinization of starch allows for better digestion and hence better results (Pieper and Pfeffer, 1980 b; Bergot and Breque, 198.3). The inclusion of the disaccharide sucrose in salmonid diets, as the present trial indicates, can yield increased growth and improved feed conversion results. In developing countries sucrose is less costly than in the U.S., where the price is 
artificially high due to government subsidization, and the use of this sugar as a fish feed additive may preclude such costly techniques as cooking or gelatinization to make the CHO more digestible. A molecule of sucrose, upon digestion, yields one glucose molecule and one fructose molecule. Hence $50 \%$ of the CHO supplied in the diet is digested to fructose which is readily taken up at the cellular level and entered into glycalysis without the use of insulin, which is usually at minimal levels in fishes. The glucose supplied by the sucrose in the diet requires the aid of insulin for utilization. Treated (MT, sexually sterile) fish were included in each trial to determine the effect of treatment on glucose utilization in these fish, and how this would influence growth.

Addition of glucose to salmonid diets has given conflicting conclusions. Bergot (1979a) stated that maximal growth and feed conversion can be achieved at glucose levels as high as $30 \%$ of the diet. He also stated, though, that a depressive effect on food intake can occur at high dietary glucose levels. In the present study no such anorexic effect was observed in either the high-sucrose or high-molasses diets; aggressive feeding occurred throughout the feeding periods. Hiltan et al (1982) suggest that the maximum tolerable level of glucose in salmonid diets appears to be dependent on protein, lipid and overall energy content of the diet, and may be in 
excess of $25 \%$ of the diet for raintow trout. Another study indicated that rainbow trout have a linited ability to adapt to increased dietary CHO, arid levels in excess of $14 \%$ of the diet is not efficiently utilized (Hilton and Attinson, 1982). From the data and results presented in this paper, it ig clear that in all cases utidization of grose energy, provided in equal amounte in all diets, was much better in fish fed high-CHD (sucrose and molasses: diets as opposed to high-fat diets. This agrees with studies by Fieper and Ffeffer (1900a) which showed increased utilization of dietary gross energy in rainbow trout fed a high-sucroes diet over those fed diets high in glucose, gelatinized starth, and Even sunflower ail. These authors believe that sucrose and other digestible dietary CHOs strow a certain superiority witl' respect to sparing of dietary protein as compared to lipids. They also showed that digestion is not a limiting factor for these CHOs in trout, because they were more efficiently utilized than glucose. Ey feeding sucrose as opposed to glucose directly, a sudden flux of glucose into the fish's metabolic system may be prevented, hence avoiding the negative phiysiological effects of such a flux. Fiaintow trout fed a $30 \%$ glucose diet (Bergot, 1979t) quict:y developed (within 6 hours) a pronounced glycemia after feeding.

In the first feeding triat (storose vs high-fat), 
though equal amounts of metabolizable energy were provided in each diet, the high-sucrose diet outperformed the high-fat diet in all respects. Fish (treated and control combined) fed the high-sucrose diet showed significantly improved actual weight, relative weight gain (gain/initial weight), length gain and feed conversions (Table VI; Figures $2,3,4)$. In sucrose fed fish, both actual weight gain and relative weight gain were significantly enhanced. Relative gain was the highest for treated fish on the sucrose diet, perhaps indicating better CHO Litilization in this group. Means for overall feed conversion and protein conversion efficiencies were much improved in sucrose fed fish (1.25) than those fish fed the high-fat diet (1.39). Though plasma glucose levels were significantly higher in sucrose fed trout (Table VII, Figure b) as compared to high-fat fed trout, levels were not abnormally high (ave $92.5 \mathrm{mg} / 100 \mathrm{ml}$ plasma), an indication that good digestion and rapid assimilation of dietary sucrose occurred. Normal plasma glucose levels in salmonids a few hours after feeding is between $80-100 \mathrm{mg}$ per $100 \mathrm{ml}$ of plasma. Measurements of visceral fat $1 \%$ of body weight-Table VII, Figure () yielded no significant differences between the two diets, indicating that dietary sucrose was used by the fish to fullfill daily energy requirements and was therefore not stored as visceral fat. Visual inspection of fish livers. was made at necropsy and 
no distinct gross differences were observed between $f$ ish fed the two diets. The incidence of low visceral fat levels in sucrose fed fish may signify that sucrose is being used energetically as efficiently or better than herring oil in supplying metabolizable energy to the fish. Sucrose may be more efficient in sparing dietary protein, which in turn could be used for tissue building processes instead of merely as a highly expensive dietary source of energy. Fieper and Fifeffer (1980a) arrived at identical conclusions in their work with rainbow trout. These results, and considerations of monetary aspects such as the high cost of quality oils in some areas, should lead to an increased use of highly digestible CHOs in salmonid and other cultured fish diets. Eecause the two diets were isonitrogenous, fish fed the sucrose diet naturally had more efficient protein conversions.

In the second feeding trial, where molasses was incorporated as an alternate digestible CHO source, both of the high CHO diets demonstrated significantly increased actual weight gain and actual length gain than the high fat diet after nine weeks of feeding rainbow trout (Table VIII, Figure 7). Calculation of relative gain (Figure 9) for this feeding trial indicated that both of the high-CHO diets had significantly improved gain than the high-fat diet. The molasses diet also showed higher relative gain than the sucrose diet in this regard, due to the superior 
growth of treated fish on the malasses diet. Therefore with respect to relative gain, molasses (1.5.) ? sucrose (1.44) Yhigh-iat (1.16). Felative gain was used as an indicator of growth in order to account for variant initial weights of treated sind control fish at the start of the experiment and rul out any advantage larger pish might nave.

Dver the rime weet period of the second trial feed conversion effiajencjes and hence, protein conversion efficiercies, were stiperior in the high-CHO diets (Table VIII, Fighre a) " Gveral fekd conversion of the high fat diet was in 4 ? whine those of the high-gucrose and molasses diets were 1.20 and 1.18 respectively. These differences may be due to increased utilization of the CHDs in the sugs and nol asses diets by treated fish. These results concide with the high actual and relative weight gains of the tish fed bhese diets. Calculation of condition factor for the three diet groups yielded no significant differences, indicating that lengthuweight ratio was not influenced by diet. Therefore visual appearance and marlat value of fish wolld rot be affected by feeding a high sucrose or high molasses diet. Elood gluccse and visceral fat levels were also calculated for the second trial iTable IX, Figure 11). Vigceral fat levels were the highest for those fish fod the high-fat diet, indicating that cho utijazed in the dift was not laid down as visceral rat but. 
was used as metabolizable energy to meet the day to day energy needs of the fish. In agreement with the first feeding trial, fish fed the high-CHO diets had higher plasma glucose levels than those fed the high-fat diets, though values were not abnormally high ( $97 \mathrm{mg} / 100 \mathrm{ml}$ of plasma). This once again indicates increased utilization of dietary CHO after digestion occurs.

Fesults from the two feeding trials presented hera almost conclusively show that $f$ ish diets high in digestible and utilizable CHOs such as sucrose arid molasses give growth performance better than a high lipid (fish oil) diet of comparable calorir quantity and quality. Herring oil, the diefary lipid used in this study, has been used successfully in high caloric amounts in sparing dietary protein (Kellems and Sinnhuber, 1982) but this feed additive may be prohibitively costly or unavailable in many areas. The present study agrees with other research (Fieper and Fifeffer, 1980a and 1980b) in demonstrating the superiority of sucrose (molasses is 50-60\% sucrose) over lipids as a protein-sparing dietary energy source. Mol asses appears to show the same effects in this regard, as results from the second feeding trial would indicate. Incorporation of molasses into fish diets has not been researched prior to this work and therefore literature reviewing this aspect is unavailable.

Sucrose has been demonstrated to be a superior feed 
additive over glucose and starch also in the tilapia, oreochromis niloticus (Anderson et al.,1984). These results along with those given in other studies using rainbow trout (Fieper and Ffeffer, 1980a) indicate that, contrary to Edwards et al (1977), sucrose is more efficiently absorbed and utilized than glucose in these important aquacultural species. The data presented in this thesis research tends to correlate and complement the view that sucrose is indeed a superior feed additive for providing dietary calories to the fish. Molasses, containing only 50-60\% sucrose, must be added in higher amourits to fish diets to provide equal caloric value. But this waste product of the sugar refining industry is relatively inexpensive in most areas and is palatable to the fish, making it also practical for aquacultural use. The use of these quality CHO ingredients along with the cheaper, high quality cooked or uncooked protein mixes which Fobinson et al (1785) investigated, might provide the aquaculture industry with an inexpensive and high performance fish feed.

The availability and cost practicality of sucrose, molasses and other highly digestible CHOs such as brewers solids, makes the possibilities for use of these products as $f i s h$ feed ingredients near 1 imitless. The evidence submitted here and in other studies has shown the advartages of using such additives in any fish diet 
formulation. Diets using these ingredients are easily prepared, can produce a good feeding pellet, and will provide physical properties superior even to high-fat preparations. Incorporation of these products produces a feed which is highly palatable to the fish and gives more than adequate results as compared to conventional pelleted feeds used today.

The effect of MT treatment on fish used in these feeding trials appeared to elicit the desired response to the different diets. In all cases growth parameters indicated that treated $f$ ish did much better on a high-CHO diet than on a high fat diet. In the first feeding trial, MT-treated fish had much poorer mean feed conversions when fed the high-fat diet (1.50) than when fed the sucrose diet (1.24) and also did better than control fish fed either the high-fat or sucrose diets (1.23). The same was true with respect to actual weight gain in the first trial. Treated fish fed the sucrose diet showed significantly better gains than any other group. Plasma glucose levels were significantly lower in treated fish on both diets, which suggests improved glucase uptake at the cellular level. Fercentage of visceral fat was significantly lower for treated trout $(\sim 1.20 \%)$ than for control fish $(\sim 1.68 \%)$, another indication that the treatment given earlier in the fish's 1 ife has had some effect on dietary CHO utilization, and the laydown of visceral fat. The first feeding trial 
clearly indicated an advantage of using MT-treated trout over non-treated trout when feeding a digestible carbohydrate diet.

In the secand feeding trial, results did not show such a clear-cut advantage of treated fish over untreated but, generally growth parameters were better for MT-treated fish than controls. Feed conversions were slightly improved overall (though not significantly so) and actual weight gain was increased for treated fish fed all of the different diets (also not significant). With respect to relative weight gain, treated fish fed the molasses diet showed significantly improved performance over all other groups. This agreed with results obtained for relative gain in the first trial, using sucrose as the sole CHO source. Contamination of a feed ingredient may have negated the effect in the sucrose fed $f i s h$ in the second feeding trial. The overall mean showed that, in general, treated fish had significantly better relative weight gain than control fish when both were fed a high-cHD diet (Table VIII). Analysis of visceral fat and plasma glucose data gave no significant difference between the treatments, although the lowest visceral fat levels occured in the treated group on the sucrose diet. Flasma glucose levels remained within normal range for all groups tested. Condition factor was not significantly different between treated and control groups showing that neither treatment 
nor diet, as was shown before, would rave an effect on the overall health ard visual appearance of the fish.

In a related feedirig study using commereial peeds with treated arid control fish, there was evidence that treated fish performed better than controls with regpect to growth and feed converatom on the diets which were highest in

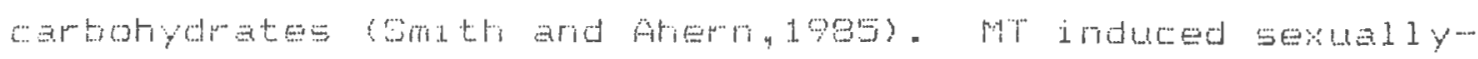
gterilized 7 ish had improved ectud and relative weight gins tham Gontorle on al three or the comercial diets

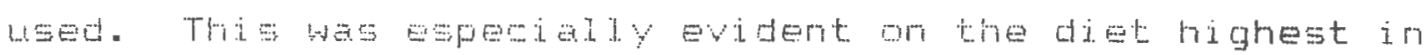
CHO Theated tish also had lower levels of visceral fat (as\% of body weight) then control figh fed the sane diets. Explanation of why treated (cenul lyoteriles fish perform better on a highoHo diet have been alluded to jo the introducton and literature review of this thesis. Treatment with mr at the onete of feeding in young fish may have affected the normal tendocrinological controls in these fish. Along with possible bloctage of mormal testosterone production ir these fish, preventiog sexual maturity, it is possible that normel cortisol production is somehow disrupted at an early age through feedbact control or other mechanjsms. Cortisol and testosterone follow the same biosyothetic pathway for a tine befome brealing off into separate pathways et later steps of synthesis. If a comon intermediate of both end products is intibited, then production of both products might be affected. Feduced 
circulating cortisol levels throughout the life of the fish would allow other, anabolic type homones, such as thyroxin, insulin and somatomedins to have greater influence. This would in turn initiate increased protein symthesi and hence, better growth. Aiso, of couree, fish

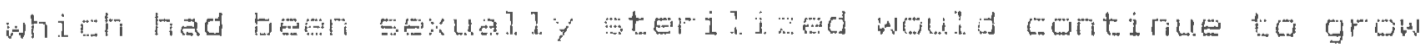
during the period a normen fish waud put energy into gonadel tissue developmen. Therefore a larger, healthier fism is produced iri a shorter time gpari.

It is clear that further research into this area must be dome before any positive conclusions can be drawn about how the mechanisms wark which allow for better growth of treated fish over those wirich have not been treated. What can be concluded from this study is that in most cases under the sane conditions, MT-weated (steriles fish will outwperforin comtor fjoh on a diet high in digestible CHO. This study aloo shows that a high-sucrose or highmolassen diet will produce an Enhanced growth response than a high fat diet of comparable energy value. It also dispells the tielief that salmonids requiren and only do well on a high-protein diet to the exclusion of all else. Lower levels of crude protejn which contain adequate amounts of essentiai amino acids may certaindy be used in conjunction with higher levele of digestible carborydrates. Also, the use of freege branding in the second trial of this study has shown this method of menting rantow trout to be a 
valuable tool in obtaining individual statistics for analysis of experimental data (see Apendix I). Feeding studies and other mesearch using fish, which extend over a 12-20 weef period, may be analyzed individually to account for differences due to diet and/or treatment. With proper technique, this method provides clear brands for at least 16 weels and would preclude infection and disease problems encountered in conventional tagging methods.

In future such MT-treated versus control type studies, it is suggested that experimental design takes into account several aspects which have been overlooked in this study. Ferhaps, because treated fish have been shown to be more docile and less aggressive than controls of the same age and spawning group (Smith, 1983), as part of the study, treated fish should be maintained apart from controls in order to determine how this aggression aspect would affect growth performance. It is also recommended that, as has been done in other carbohydrate feeding studies, 1 iver weight and hepatic lipid and glycogen levels should be measured, in order to determine the effect of diet on this organ with respect to CHO utilization. In order to determine positively blood parameters which control. CHO utilization in treated or control fish, perhaps plasma cortisol, testosterone, thyroxin and/or gonadotropin (GTH) levels should be measured. Muscle tissue or whole bady analysis of fish after termination of each trial could be 
done to determine the effect of each diet on quality and quantity of body flesh. Dressed, carcass weight could also be determined at termination as a measurement of feed and protein conversion. One may conclude that al though good evidence of the superiority of diets high in digestible carbohydrate, and better growth performance of treated fish has been demonstrated in this study, further research into the nutritional and hormonal aspects of fish culture must be continued. To help meet the increasing demands for high-protein foods in the modern world at minimal cost, these nutritional and hormonal applications may be instituted in fish culture operations" 


\section{BIBL IOGRAPHY}

Ablett, F. F., M. J.Taylor and D. F" Selivonctich. $198 \mathrm{~s}$ The effect of highiprotein and high-carbotiydrate diets and (x): iodoinsulin binding in steletel. muscle plasma neitibrenes and j.sol ated riepatacytes of rainbow trout (salmo garineri). Erit. Jour. Mutr. $50: 129-159$

Ald atren, W. T. 1962. The frirenal Cortex. From: Hardtoot: of Endor inology" Edited by George H. Glass and Harolut Maplan. CFC Fress Ine. 1902.

pp. $199-228$.

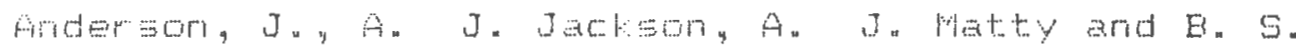
capper. 1984. Efecte of dietary arbohydrate ard

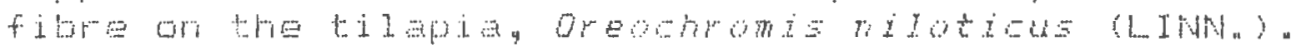

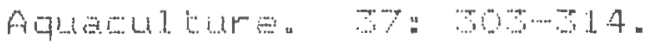

Austrerg, En, $3 . F i s a$, D.J. Edwards and H. Huidsten. 1977. Carbohydrate in rajobow trout diets. II.

influence of carbohydrate levels on chemical composition and feed utilization of $f j$ sh from differerte fairilies. Aquaculture. l1: 59-50

Bergot, F. 1979an Carbohydrate in rainow trout diets: Efrecte of the 1 evel ard source of carbohydrate and the number of mesl a or growth and body composition. foluaculer

.1979b. Effects of dietary carbohydrate and of their mode of distribution on alycenia in rainbow trout

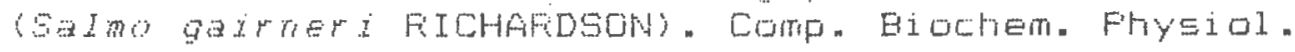
$64 \mathrm{~A}: 543547$.

and J. Ereque. 1933. Digestitility of starch by rainbow trout: effects of the physical state of starch and the intake level. Aquaculture. Ia: 203-212.

Eillard, Fi, B. Bretan and M. Fichard. 1981" On the inhibitory effect of some sterbids on gpermatogenesia in adult reinbow trout (Galno garbineri) a Can. J. zool. 59: 1479-1437.

, W. Fichard and Fi. Fombute. 1982. Inhibition of spermatagenesis and vitellogenesis in rainbow trout by hormonal aditivg in the diet. Frog Fish-Cunt. $44(1): 1.5-19$.

Brown, F.5. Fu. Strage and K. F. Rubbins 1985. 
Frotein digestibility coeficients for yearling ghannel. catfish fed high protein feedstufte. Frog. Fish-..Cult. $47(2): 94-97$.

Eut]er, D. G., W. C. Cilart, E. M. Donaldson and Fi. W. Langford. 196\%. Burgical adrenelectomy of a teleost fist (AT gulla rostrata LeSuelir): effect or plasia corti. al and tissue eilewtrolyte and carbotydrate concentratoms Gen. Comp. Endocrin. 12: 50s-514.

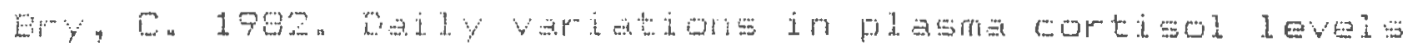

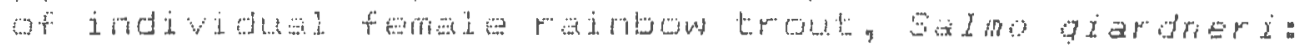
evidence for a post feeding peat in well-adapted fish.

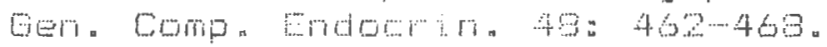

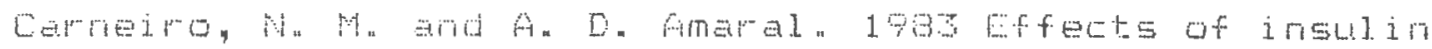
and glucogom on pirsma glucose Levels and glycogen content in organs of the freslubter toleost pimegodus

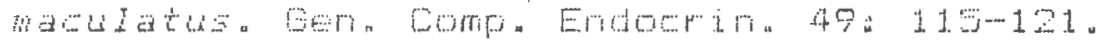

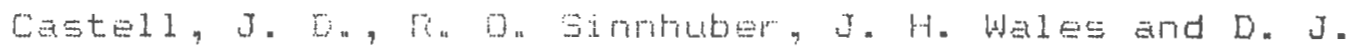
LeE. 1972. Esential fatty acids in the diets of

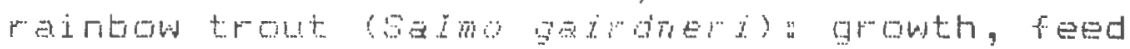
ombersich and some grase deficiency symptoms. Jour. Nuterition, $102477-65$

Chancen O. En, En T. Mertz ard J.E. Halver. 1764. Mutrition of aelmonid fienesa X. I. Isoleucine, leucine, and phenyla alomine requireinents of thinout salmon and interrelations between isoleumine and leucine for growth. J. Nutrition. $95.177-135$.

Dasmahapatra, Ant. and An . Medda. 1992. Effect of estradiol diproprionate and teatosterone propriorate on the glycogeri, Lipid, and water content of liver, muscle, arid gorad of male and female (vitellogenic and nor-vitel.logenic) Singi fish (Heterapteustas fossilis Etolit). Gen. Comp. Endocrin. 48: 476-484.

Degani D. and M. L. Ga11agher. 17gs. Effects of dietary 17 a-methyltestosterome and bovine growth hormone on growth ard food conversion of slow- and normal lygrowing American elvers (Anguilla rostrata). Can. J. Fi Sh Aquat. Sci. 42: 135-189.

Deloecler, w. 2964. The effects of testasterane on the incorporetion of glyeine-u-wa into the proteirs and rucledc acids of steletal musele. Arch. Tnt. Frarmacodyri. Therep. 150 (1): 69.78 .

Delong, D. C., J. E. Helver and E. T. MErtz. 1959. 
Nutrition of ealmonid fistes. WII. Nitrogen supplements for chinoat salmon diets. J. Nutrition. 69: 666-669.

DeSilva, 5. 5. and M. H. Ferera. 1905. Effects of dietary protein level on growth, feed conversion and protein

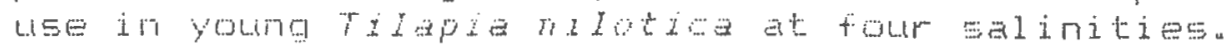

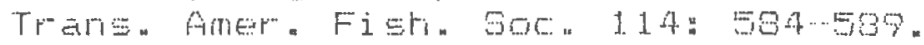

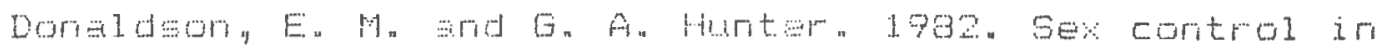
figh with perticlilar reference to salmonids. Can. J. wish. Aquat. 60 i. $39.99-110$.

Dupree, H. r. and J. E. Halyer. 1970. Amino acids esentia for the growth of charrel catfish,

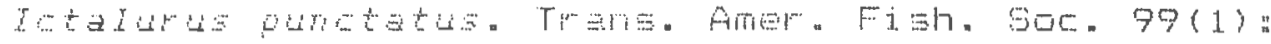
90.92

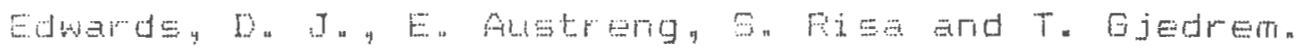
1.977" Cambohyrate in rainbow triut diets. I. Glowth

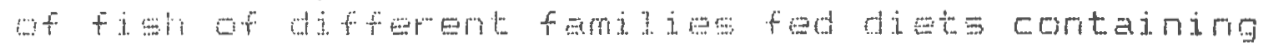
different proportiore of carbohydate. fquacul ture. $11:-1.30$

EL1. digestibility jn trout using a metabolic chamber. Frog, Fish Cult. $76(2): 116-119$.

Fagerlund, U. H. M. and J. F. FicEriden 1978. Distribution and diseppesmaree of radicactivity in blood and tissues of cono salmon (orathyrohus kisuth) after oral adininstwetion of rHotestosteme. J. Fish. Fies. Bd. Can. 3 a $993-900$.

J. Fi. MeEride and E. T. Stone. 1979. A test of 17 a minetryltestosterorie as a growth fromoter in a coho salmori hatchery. Trans. Amer. Fish. Soc. 108: 467-472.

D. A. Hjgge, J. F. McEride, M. D. Flotniloff, B. S. Dosanjh and J. Fi. Marbert. 198. Implications of varying dietary protein, lipid, and 17 a-methyltestos terone content on growth and utiliaation of protein and energy in juvenile coho salmon coreorhymohs kisutch). Aquaculture. To: 109-124.

Futuithi, w. ard Y. Yone. 1992a. Changes in activities of hepatic enymes related to cambohydrate metabolism of fishes in glucose and insul inglucose tolerance tests.

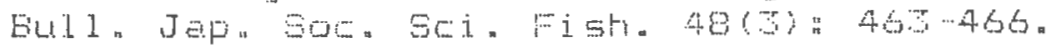

and $Y$ "Yonen ipost. Effect of insulin on blood

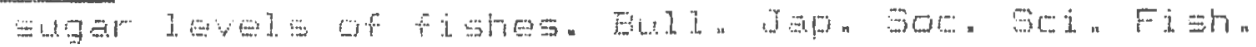
49(7) $129 \%$. 291 . 
Gala, F. F. and U. Hestphal. 1965. Copticosteroid-ininding globulin in the rat. studjes on the Eex difference. Endocrinology. $7 \%$. $341-351$.

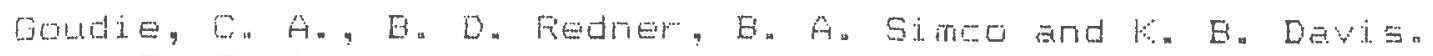
1983 . Feminjacion of channel cetrish by oral adminigtration of steroid sex hormanes. Trans. Pmer. Fish. 600. 112: 670-672.

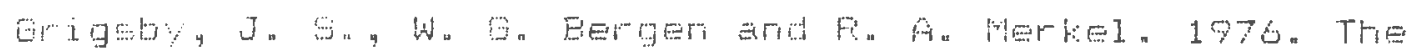
effect of testosterone on steletal muscie development and proted in rabits. Growth. 40. 303-3lb.

Hartin, F., C. Whiberead, H. Fu Ergmage, E. Smart, r. Johnstone and T. Simpson. 1980. Sterilization and other effects or methyltestosterone in rainbow trout. J.

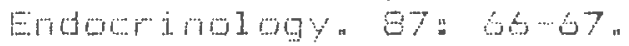

Hendrichs, Dn M., J. W. Copper, J. C. Spitzer and L. W. orimes. 19g4. Ser differences in plang corticol and growth in the worine. Jour. Anim. 5ei. 59(2): 376-385.

Higge, D. A., U. H. M. Fagerlund, J. M. MeEride, M. Dye and E. M. Wonaldeon. 1977. Tnfluence of combinations of boyrie growh hormone, 17 e-methyltestosterone and L.-thyrocine on growth of yearling cotio salinon concor...

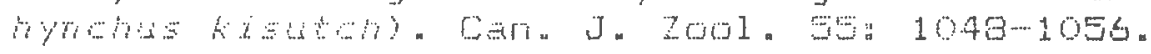

" U. H. M. Fegerlund, j. G. Eales and J. Fi.

NeEride. 1.982. Applitation of thyroid and steraid hormures es anabolic agentes in fish culture. Comp. Eidocheri. Fhysiol. 73 B(1): $143-176$.

Hilton, J. W. arid J. L. Attinson. 1982. Fesponse of rainbow trout (Salmo gardnerj) to increased levels of available carbohydrate ir practical trout diets. Erit. J. Nutr. 47: 597-607.

, J. Lu Atrinsan and S. J. Singer. 1982.

Maximum toleratle level, digestion, and inetabolism of D-glucose (cerelose) in rainbow trout (SaImo gaironeri) reared on a practical trout diet. Can. J. Fist. Aquat. Sci. $99.1227-1234$.

Hirose, Kand H. Yatashi. 1969. Frysiological studies on growth promoting effect of protein-anabolic steroids on fish-wI. Effects of 4-chlorotestostarone acetate an

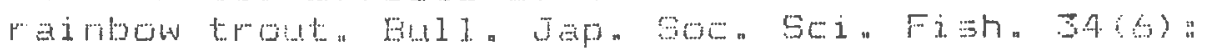
$47 .-479$.

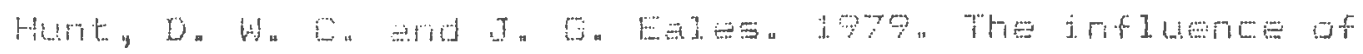


testasterone proprionate on thyroid function of immature rambow trout, sajmo garjateri fichardson. Gen. Comp. Endoerin. $37: 115-121$.

Jalabert B. "R. Bilard and B. Chevessus.1975. Freliminary experiments ono sex control in trouts production of steride fistes and simulariecus self frertiliazble hermaphodits. Arn. Eol. Frim. Biochem. Eiophys. 15. $19 \cdots 29$.

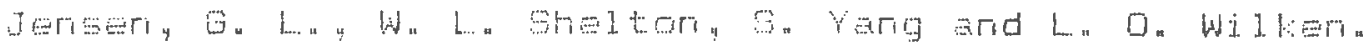
1.99\%. Ses reversal. ot gymogratic grase carp by implentation of methyltestoterome. Trars. Amer. Fish. 60, $112: 79 \cdots 65$

Johnstome, r. "T. Hi. Bimpsor, A. F. Youngson and $C$. whiteread. 197e. Sex reversal in salmonid culture.

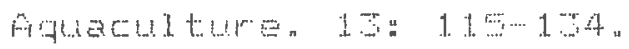

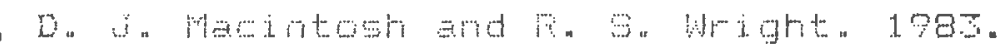

E.i.mination of omally administered 17 amethyltestosterone by oreochromis misambioss (ti 1 mpia) and

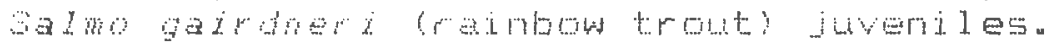

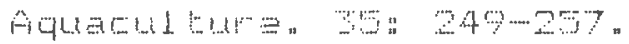

and A. F. Voungeori. 1904. The progeny of $5 e x-$ inverted fenale fitlantic almon (Salmo salar L. . .

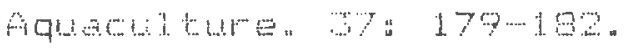

Fand'yev, A. N. and $V$. Ya. Stlyarov. 1579. Development of efficient granulated feeds for the rainbow trout, salmo gairgneri, based on bacteri al and vegetable proteim with symthetic amino acjds. J. Ichthyology. 19: $140-146$.

Fellems, F. 0. and Fi. Q. Ginniruter. 1932. Ferformance of rainbow trout fed gelatin-bound diets of fish protein concentrate of casein containing 25 to 45 percent her"ing oil. Frog. Fish-Cult. $44(3), 131-134$.

Lamba, $V . J .$, S. V. Goswami and B. I. Sundararaj. 1983. Circannual and circadian variations in plasm levels of steroids (colts.soly estradiol-178, and testasterone) correlated with the annual gonadal cycle in the catrish (Heteropreustes fossidis E] och). Gen. Comp. Endocrin. 5o: 205-205.

Leech, G. L. ard M. H. Taylor. 1982. The Effects of cortisol treatinent on arbohydrate and protein metabolism in Furdulas heterdelitus Gen Compo Endocrir. 49 a $76-9$. 
Lee, D. J. and G. E. Futran. 197 . The response of rainbow trout to varying protein/anergy ratios in a test diet. J. Nutrition. 10s. 916 ...92.

Lone, methyltestaterone on the growth end body composition

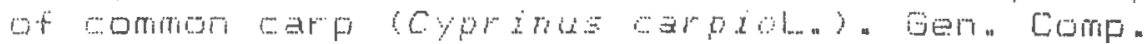
Endocriti. $40: 409-424$.

and $A$. J. Matty. d9oz. The effect of feedirg 1.1 letotestosterone on the food conversion efficiency and tossue protedri and nueleiw acid contents of

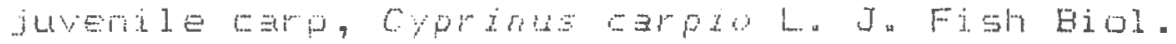
20 iो $9-164$.

Mathielas M. A. M. and A. M. Henter . 1795. Erowth rate, foed utidization and Enery metabolism of the fifrican

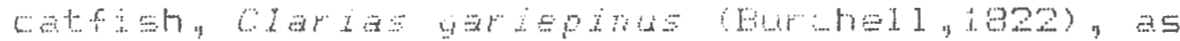
affected by dietary protein and energy content. Aqualul ture. 44 " $271 \cdots \cdots 34$.

Macintosh, D. J., T. U. Yerghese and G. F. Satyanarayana Fao. 190: Mormoral. Eex rever

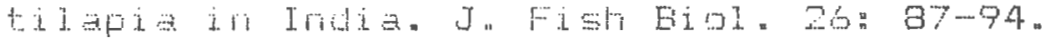

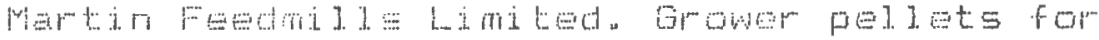
sadmonidg. Elimira and Trivistok, Canada, 1984.

Mighel. James t... 196\%. Pepid cold-branding of 5 almon and trout sith liquju nitrogen. J. Fish. Fes. Bd. Canada. $26: 27652769$

Morala, F', A. M. Vargas, M. L. Fita and F. Sanchez… Medina. 19Q2. Involvenent of gluconeogenesis in the hyperglycemia induced by glucogon, adrenaline and cyclic: fimp in raintow trutu (salmo gardneri).

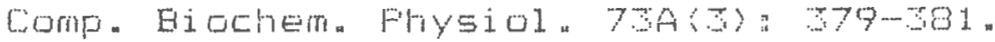

Nagai, M. and S. Ifeda. 1975. Carbohydrate metabolism in fish-IV. Effect of dietaru composition on Metabolisin

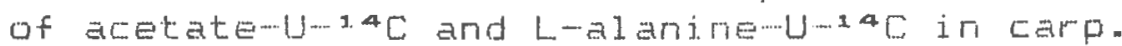
Bul1. Jap. Soc. Sci. Fish. $99(6)$ " 655-645.

Qttolerghi, $C$, A. $C$ " Fuviani, A. Baruffaldi and $L$. Erighenti" 1982. "In vivo" effects of insulin on carbohydr"we metabolism of catfish (IEtaliras

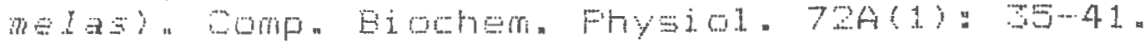

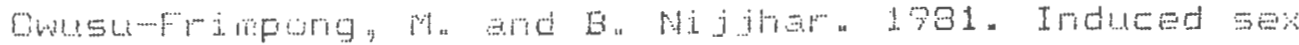
reversal in Tilada nilotas (Cichlidae) with methithesoterore Hydrobiologia $73.157-160$. 
Falmer yever y g. 19b. The effect of cortigol on body weight and mucle netabolisit in the rat. J. Endacrinology.

Fatent, Gregory J. 1970. Comfarison of some hommal effects on carbiydrate metabolisin in an elamobranch (s)ugus acanthias) and a holocephalan (Hydrotage olyei) "Gen. Comp. Endorrin. $+4: 215-24 \%$

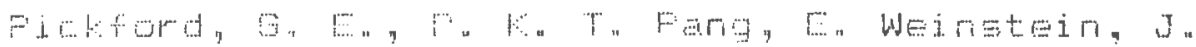
Torpetti, E. Heridler y end F. Ha Epsteinn 1.970n This responses of the hypoptysectomized cypminodont, Fududu heteraldus to replatement therapy

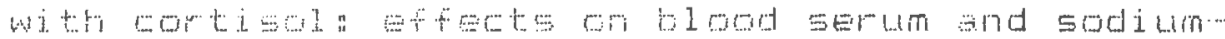
potessitum activated aderosine to imogphate in the

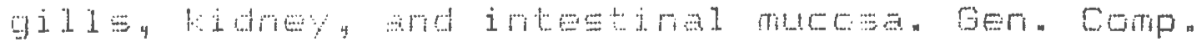
Endowin. 14:

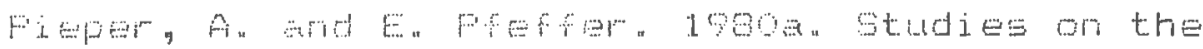
comperati efticiency af utilization of gross energy from some carbohydmates, proteins and fats

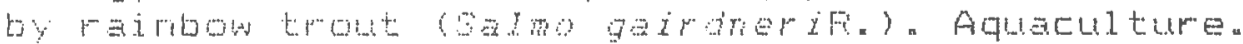
$20 \pi 30-3$

arid E. Finfer. 19got. Studies on the eftect

of increasing proportions of sucrose or gelatinized

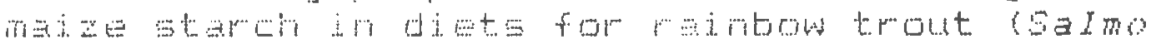

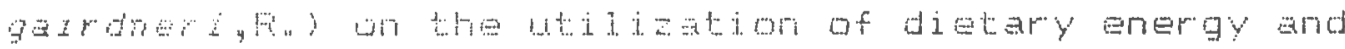

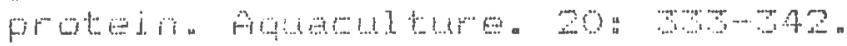

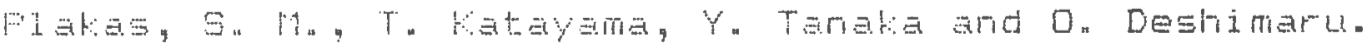
1990. Changes in the levels of circulating plasma free

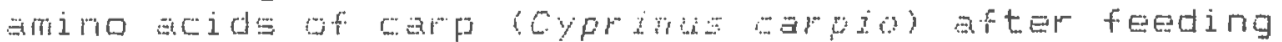
a proteim amd an amino acid djet of similar composition. Aquacultume. 21: $307-322$.

Färgens/Zeigler rish feeds Zeigler Eros Inc., Fu. Eo\% 95, Gardries. PA. 17324. 1984.

Fiao, H. N. Gathyanarayanä G. Pa Sathanarayana fiac, T. J. Varghese arid H. F. C. Shetty. 19B. The effect of 17 a-metryltestosterone on the $=$ ex of the common carp, Cyprinus arpio (L.). Evperientia. 40(3) 299.

Fiednitz, G. L., L. E. Orme, C. A. Lemir and F. N. Hitze1. 1979. Influenee of varying lipid woncentrations with two protein concentrateins in diets ror rainbw trout (Salmo garineri). Trans. Aner. Figh, S0c. 107(5):751.754.

Robirson, E. H. F. F. Aiseon and H. E. Foe. 1990. Few 
Evaluation of the lysine requirement and lysine utilization by fingerling channel catfigh. J. Nutrition. 110 . $213-236$.

J. V. Miller, V. M. Vergara and G. A. Ducharme 1985. Evaluation of dry extrusion-coofed protein mixes as replacements for soybean meal and fisti meal j. catifish diets. Frog. Fishroult. 47(2): $10-10 \%$

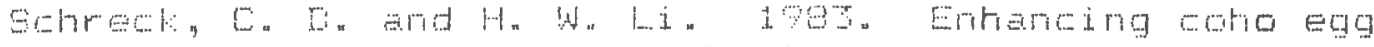
aport production and developing chum egg supply for

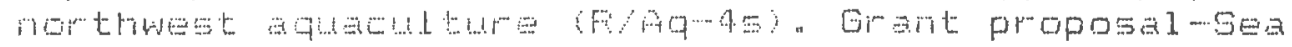
Givat, $190 \mathrm{~s}$

Shante, W. E. O. D. Gamimer and J. H. Halver. 1962. The indispenjibie aning soids For ranbow trout. Frog. Fisti-Cult. $2 \%$ :

Shcherbina, M. Au and S. Fo Tryamine. 1974. Availability

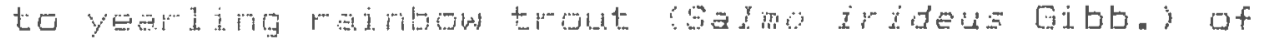

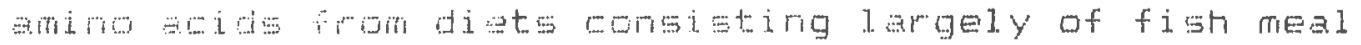
ard spleer. J. Lchthyology. 14: 10\% 114.

Gmith, L. T. 196j, Gevual sterilizaton of troot: trout

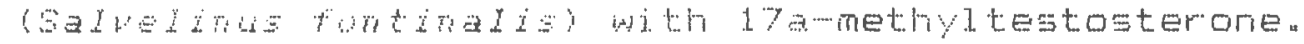

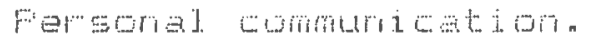

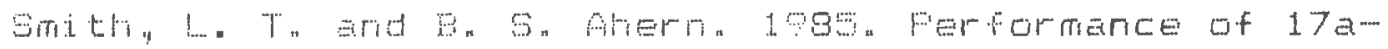
methyl testoselone-treated reinbut trout lsalmo garineri) on three diffement commercial pelleted diets. Fersonal cominumiotion on Luputalished r"esegreth daten

Solar, I. I.y E. M. Donaldson and G. A. Hinter. 1985. SEn control in rainbow trout for mariculure in British Collumia. Salmonid reprodution, an international symposium. Univ. of Washington. Wash. Sea Erant Firogram. 1983.

Sorenson, F. W. M. Bianchini and H. E. Winn. 1983. Individually martirg fimeritan eel g by freeze branding. Frog. Fish-Gultw 45(1): 62-03

Sower, S. A., C. E. Schrect and M. Everisori. 198\%. Effets of steroids and steroid antagonists on growth, gonadal

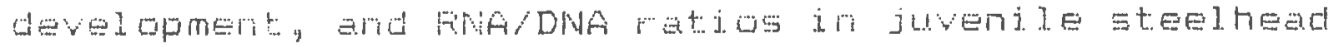

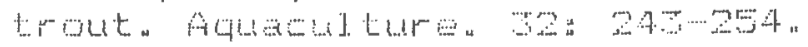

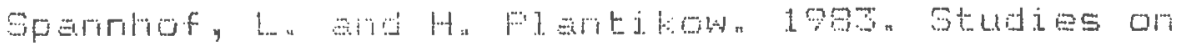
carbohydrate digestion in ranbow trout aquacul ture. 
$30995-109$

Specter. J. L. and E. B. Satrect. 1932. Changes in plesma corticosteroids during smoltifioation of como salmon, oromphrohus tesutoh. Gen. Comp. Endotrin.

$46: 53.0$.

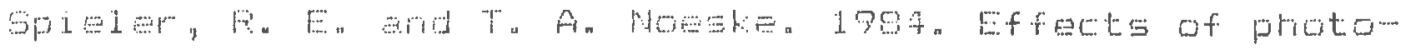
period on diel variation of locomotor activity" cortisol, and thyropine in golutish. Trans. Aner. Fjen. 90. 1.1.

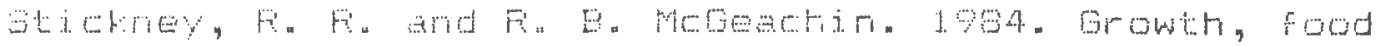
corversion and suryal of rimgerling rilapia aurea

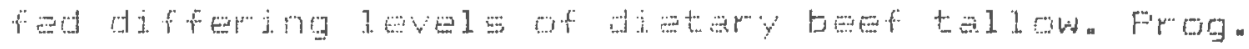
Fish-Cult " 40 (2)

Stinson Trout Line Feeds. Stinson Caning Co y Fish

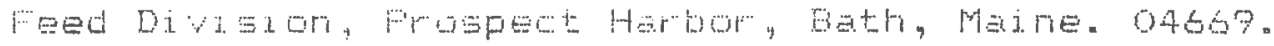
1.794 .

Stcmer, Joyee H. 1967. Staryation and the effects of

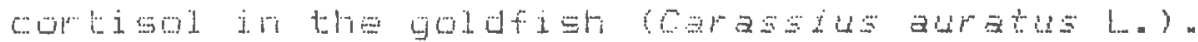

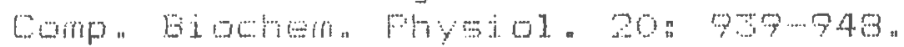

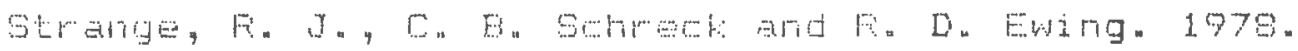
cortssol comcentratione in worfined iuvenile chimoot:

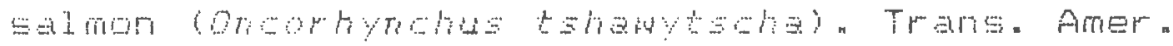
Fiwh. 900. 107(6): $912-919$.

Stryer, Lubert. 1981. Hormome Actudon, from Bi ochemistry Z’no edition. pp. $474-477,940-350$. W. H. Freeman and Company.

SLndaramaj, E. I., S. V. Gostami and V. J. Lamba. 1982. Fiole of testosterpne, Estradiol-178, and cortisol during vitel.logenin synthesis in whe catfish, Hezeropreustes fossizis (Bloth). Gen. Comp. Endrerin. 43: $990-597$.

Tasticina, L. and G. F. Cahill, Jr" 1968. Effects of insulin in the toadfish, opsamus taci. Gen. Comp. Endocrin. 11: 262-271.

Wagner, G. F. and B. A. Mckeowri. 1902. Changes in plasm insulin and carbohydrate metabolism of ainc-stressed

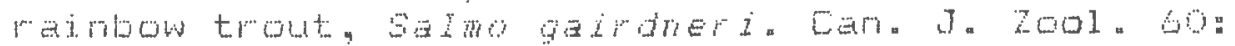
2079.2084.

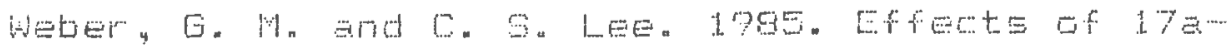

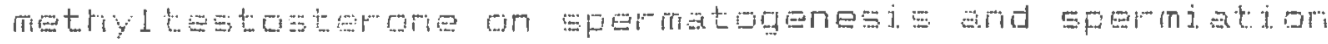

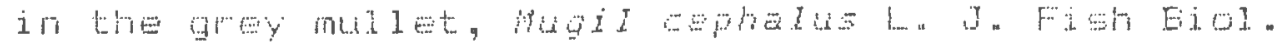


$26: 77-94$

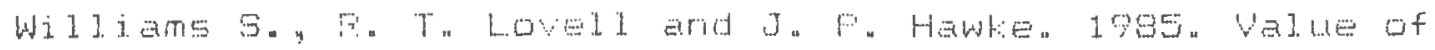
menhaden oj. in diets of Flarida pompano. Frog FishCult. $47(5)$ \% $199-165$. 
Appendix I -... The use of a fregzewtanding mechanism as a meang of marking rainbow trout for later j.mividual identification.

ln a predinjarry feeding trial which was not ineluded in this thesis reporty brook trout

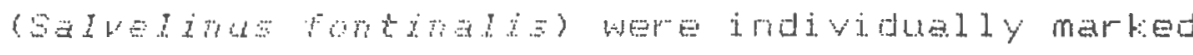
with plestic, mumbered tags at the gtart of the trial. Taga were manual y intidded just ventoral to the dorsal fin into the dorsal muschiature ueing a taggirg gun. The needle of this gun was injected under the stin and into the musele and anchored there through a twisting action of the gun. Within thres weets of the taging high mortality began to occur. The area around the tags became irfected with bicteria (Aeromoras spp.) and ulceration and necrosis of the tissue resulted. Tags often fell out, and by the end of the feeding t.rial at leate $50 \%$ mortality otcured in each tank. Frimary baterial infection was often followed by

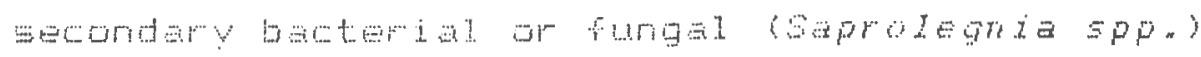


infection. Fish were often anorexic and showed poor growth. Due to the initial stress of the tagging technique and the open site for infection where the tal is inserted, fish pathogens ma easily infect the fish and oabse high mortality. This method of individuglay

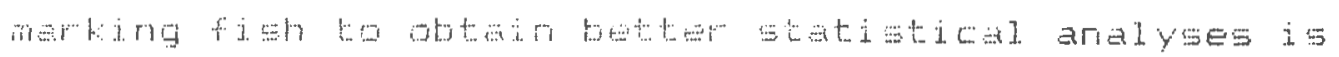

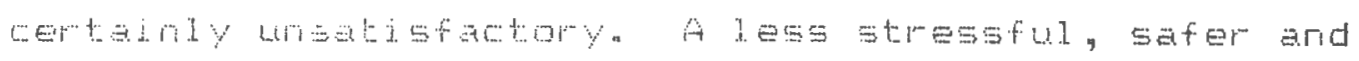
more gffertive methind of marbing must be used to i reure more deperidule regulds with no mortality problems. In the serond foeding trial of the present thesis

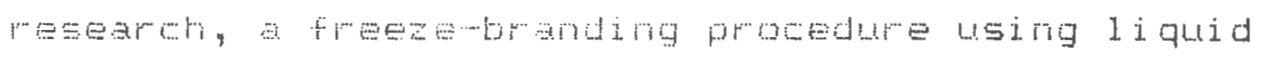
nitrogen wase utidized to individuelly marb all of the fish in each tonk. The freeze brariding apparatus was eas. 1. conetructed and inexpensive to mate "The outside shell of the device was simply a cyllidrical

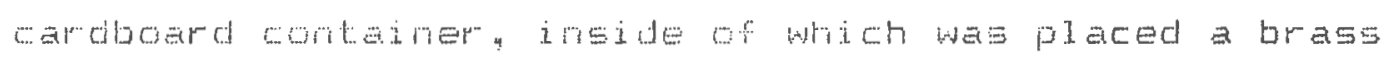
weservoir to hola the liquid nitrogen. Eevween the outside cardboard shell and the inside brass reservoir Has placed about 5 cin of polyurethane material for insulation. The polyurethane was cut to fit tightiy and all cracts were filled with a polyurethane spray foam. The diameter of the outside cardboard container was 20.5 cin and the trass reservor was 10.0 ch in dimeter, constructed of o, 25 cri solid brass material and rolded into a cylindrical form with a bap soldered wh at the bottom The reservoir was about 130 com in 
depth and could hold mome than 1. nitrogen. Eetween the bottomi of the reservair and the bottom of the cardboard container about a 0 cm of polyumethane was placed for ingulation. The total reight of the aporatus (cardboard container) was 24.0 $\cdots i \pi$

To the brase reservol , about 23 of the way down from the top a a soljo bias: rod (o. Bem diameter) was soldered to the inside wall of one through the interior of the reservoir and through the opposite wall and the insulation beyond it. This rod Was extended outsicie the cardboard container about 10.0 cm to give ample =pace for manipulation of hands and fish when bremdimg To the end was soldered a solid copper "T" whioh was used es the brand. This "T" was o. com acios the top and o.7 win from top to bottom. Dur'ing the branding operation, the section of the rod inside the reservoir ("10.0cin) was completely immersed in liguid mitrogen. The holding eapecity of the brass reservoir ( 21.0 litre) al owed for effective branding of more tham 140 fish. The whole apparatus was mounted on a plywood platform mating it fortable and safe to use.

at the stert of tre second feeding triel used for this theais, rabbou trout were individually branded for 1 ater d dentification using the following procedure. 
Ore 1 itre of liquid ritrogen was placed in the brase reservoir and capped with about is ca of polyurethane insulation, on top of which was placed the cardtoard cover, als0 lined with 25 cin of polyumethame insulation. This cooled the brass rod and copper brand to minus log degrese. Fish were ariegtiesiaed with

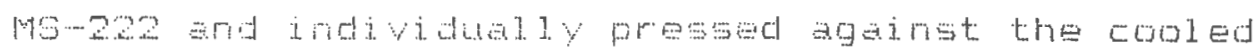

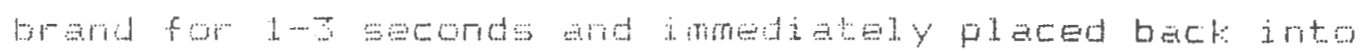
fresh weter. The brend was wiened with a wire brush arter Every 2 or $\Xi$ applitations to prevent fouling and to insure $\Rightarrow$ egr mart. The brand was applied in four differmt orientulons and at three different locations on the fish ffront of dorsal-ieft side, back of

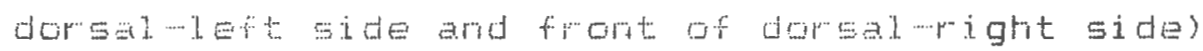
thereby gidng 12 different brends per tarit. Tating into acount the riot that treated figh had the adipose fin cut off, 24 different fish could be identified. If more identifications were newded other, different 1.ocations on the fish could be utilized. If need bey the brand could be made removable and different brard designs could be attached and Lised. Brands were easily read at each growth chect: and at termination so that individual fish could be identified. Thi a allowed for determinetion of growth par ameters and other" measurements for individual fish so that statisticed

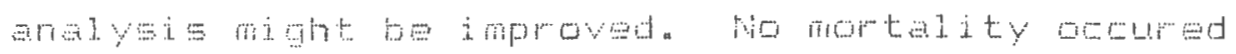


throughaut the trial due to branding ard $16=5$ stress is incurred by the fish from this procedure as compared to the preyicusly mentioned tegging methods. The sita is not broten and the wound is quickly bealed over wril atil al doling for the brand to be edsily read. This epparatus and procedume provides a feasible and safe metrod for idertification of El momid fishes for esperimental purposen. This sytam might also be utilized for other species of fish inhich have smal scales or sur sealeiss: epecies suth as catfish. Figure 12 Enows a recogrizzole brend on a rairbow traut

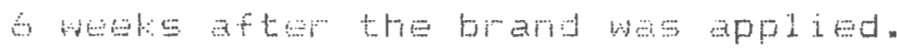


Fiqure 12 Fhoto of yearling rainbow trout with recognizable brand from freeze branding apparatus. Fhoto taken $5 i \times$ weeks after brand was administered. 


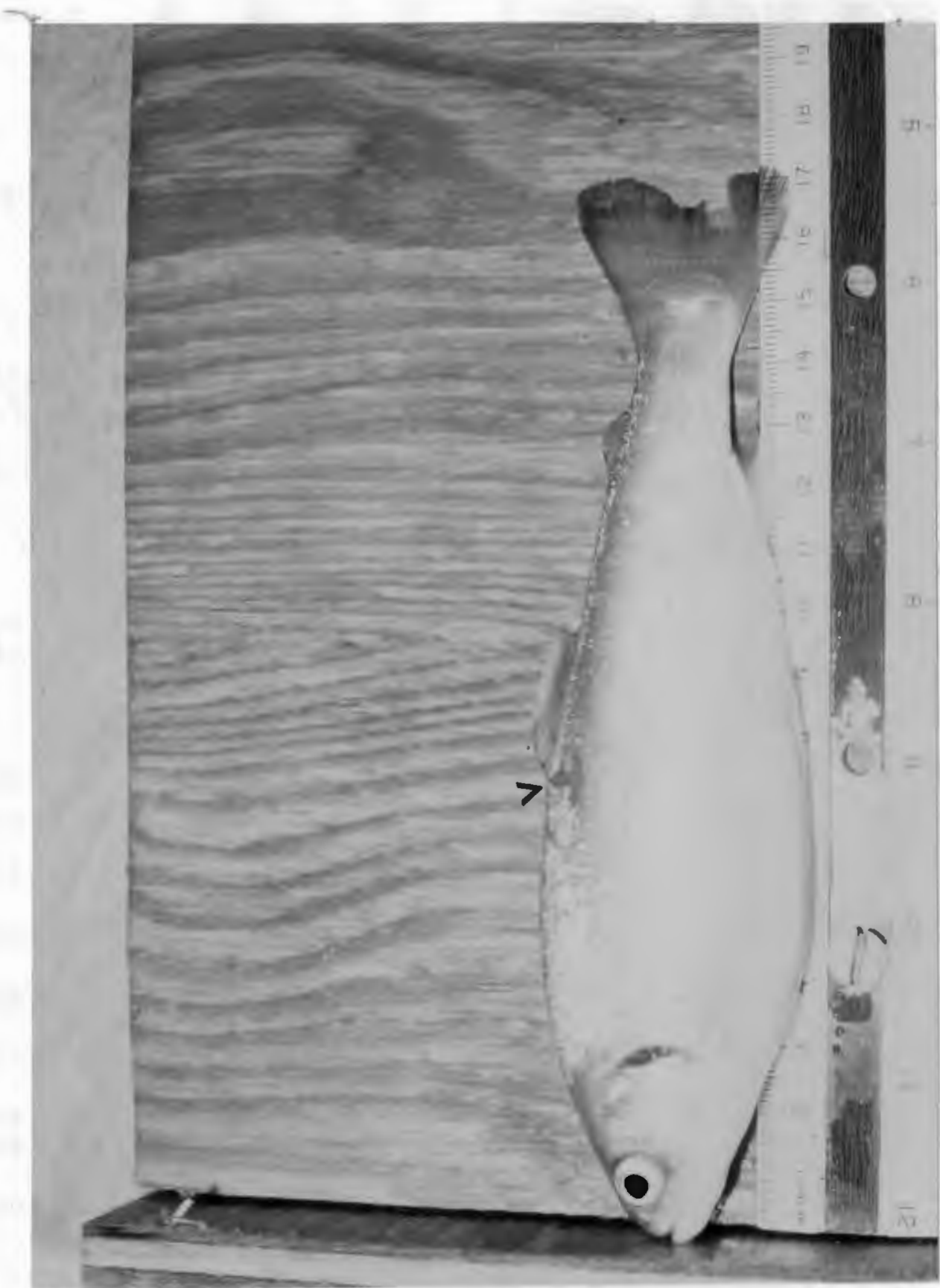


Appendix II f... fralysiz of Variance for all farameters

AПघ]ysis of varairoe for actual weight gair of

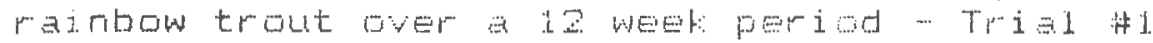

sourte df 99 Ms Fvalue g0.05 00.01

\begin{tabular}{|c|c|c|c|c|c|c|}
\hline $\operatorname{tat} a 1$ & 11 & 1000 & & & & \\
\hline$r E F E$ & 2 & 147.5 & 7. & $\%$ ? & $\equiv \mathrm{ign}$ & N. $S_{4}=$ \\
\hline feEds & 1 & 6.6 .4 & $6 \cdot 54$ & 85.7 & $=$ i. & ח \\
\hline$T \vee \subseteq C^{x}$ & 1 & 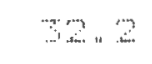 & 32 & 4. & 4.5. & $M . S$. \\
\hline $\begin{array}{l}\text { i r ter } \\
\text { action }=\end{array}$ & 1 & 147.5 & 147.5 & 1.9 .9 & जign & घign \\
\hline error or & $\varepsilon$ & 4.4 .6 & 7.4 & & & \\
\hline
\end{tabular}

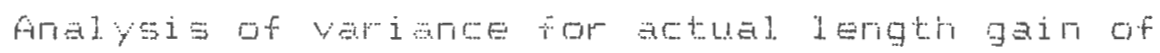
raimbow trout over a 12 weet period

\begin{tabular}{|c|c|c|c|c|c|c|}
\hline søuH & $d f$ & 89 & 19 & F va]นe & 90.05 & $\Leftrightarrow 0.01$ \\
\hline total & 11. & $2 \times 7$ & & & & \\
\hline$r \in P S$ & 2 & 0. & 0.15 & 1.57 & $N . S$. & $N .5$. \\
\hline feeds & 1 & 1.5 & 1.45 & 15.95 & sign & sign \\
\hline$T \vee \subseteq C *$ & 1 & 0.2 & 0.17 & 1.83 & $N_{n} S_{4}$ & M.S. \\
\hline $\begin{array}{l}\text { inter- } \\
\text { action }\end{array}$ & 1 & 0.5 & 0.26 & 2.87 & $N . S$. & $N .5$. \\
\hline error & b & 0.5 & 0.09 & & & \\
\hline
\end{tabular}

\footnotetext{
$x=$ treatment va control = treatment effett

$z=$ interaction effect of treatmert and feejs (additive)

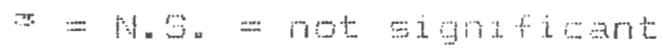


Analysis of variance for relative gain of yainbow trout over a 12 weet perigd -.. Trial \#1.

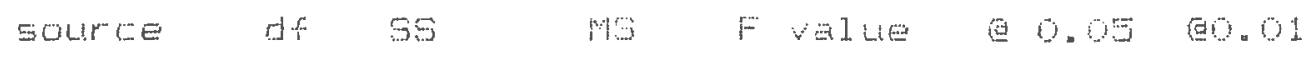

\begin{tabular}{|c|c|c|c|c|c|c|}
\hline total & 11. & $\because \geqslant 1$ & & & & \\
\hline reps & 2 & 0.01 & 0.005 & 0.2 & 4.9. & $N, S$, \\
\hline feed $\Rightarrow$ & 1 & 0,15 & $0,1=3$ & 5.4 & $N . S$. & N.S. \\
\hline 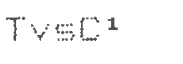 & 1 & 0.15 & $0,1=$ & 5.4 & 4.9. & $N .5$. \\
\hline $\begin{array}{l}\text { inter } \\
\text { actionz }\end{array}$ & 1 & 020 & 1029 & B. 1 & sign & $H . S$. \\
\hline erirgr & 6 & 0.17 & 0. 10 & & & \\
\hline
\end{tabular}

Anelysis of variance tat feed corversion of reinbow trout over a 12 ineet period - Trial \#1.

\begin{tabular}{|c|c|c|c|c|c|c|}
\hline sour ce & $d f$ & 69 & 19 & $F$ val. & 0.05 & 0.01 \\
\hline totel & 11 & 0.16 & & & & \\
\hline$r \in p s$ & 2 & 0.00 & 0.001 & $\% .31$ & $N . \sigma^{\circ}$ & $N .5$. \\
\hline feeds & 1 & 0.06 & 0.06 & 25.94 & sign & si.gn \\
\hline TVSC* & 1. & 0.03 & 0.03 & 7.00 & डign & $N .5$. \\
\hline $\begin{array}{l}\text { inter- } \\
\text { action }\end{array}$ & 1. & 0.05 & $0.0=$ & 14.44 & sign & $\Xi i g n$ \\
\hline error & 6 & 0.02 & 0.004 & & & \\
\hline
\end{tabular}

1. = treatment y. control = treatment erfect

z $=$ interation effect of trealoment and feeds (additive)

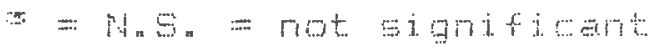


Analysis of variance for plasma glucose levels of rainbow trout at termination of experiment - Trial \#1 source df 55 MS Fvalue go.05 00.01

\begin{tabular}{|c|c|c|c|c|c|}
\hline total & $\begin{array}{r}\text { itimes } \\
41010 \\
119 \quad 1097\end{array}$ & & & & \\
\hline reps & 21.9 & 1097.6 & 34.9 & $=i g n$ & Eign \\
\hline feeds & 1405.4 & 40542.0 & 1280.5 & sign & sign \\
\hline$T v s L^{1}$ & 187.95 & 2795.1 & 293.7 & इigr & si.gn \\
\hline $\begin{array}{l}\text { inter- } \\
\text { actione }\end{array}$ & 1545.5 & 54546.7 & 1704.6 & sign & डign \\
\hline error & $114 \quad 569$ & 31.5 & & & \\
\hline
\end{tabular}

Analysis of variance for viseral fat level (\%) in rainbow trout after a 12 weel: feeding trial. - Trial \#1.

source df $5 S$ MS Fvalue e0.05 00.01

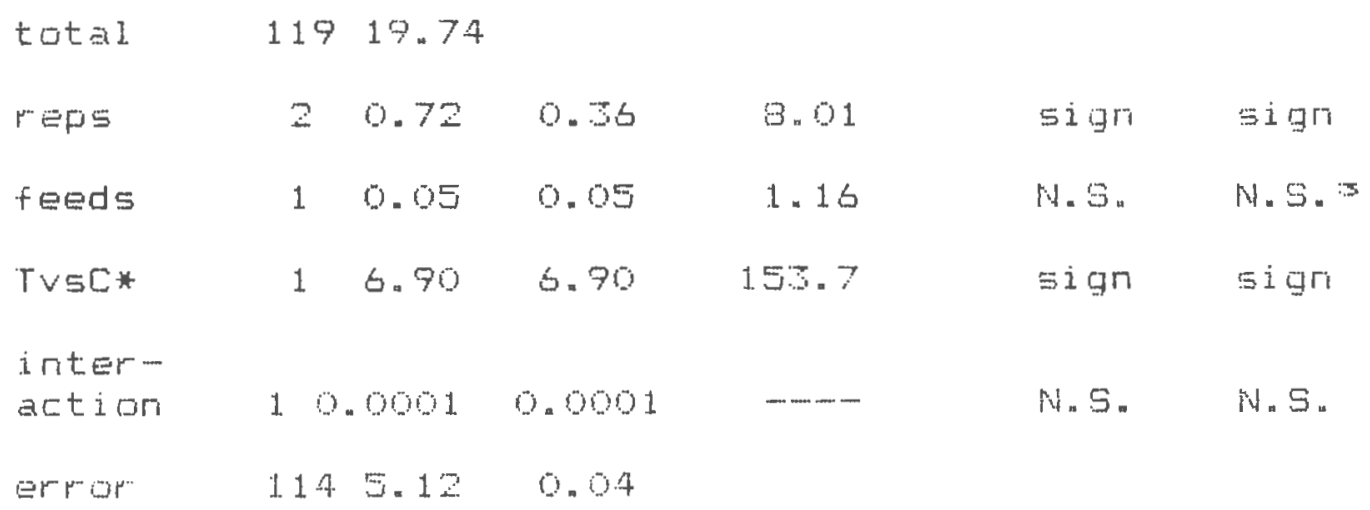

$1=$ treatinent $v=$ control = treatinent effect

$z$ = interaction effect of treatrent and feeds (additive)

$=$ M. S. = not aitgrificent 
Analysis of varaince for actual weight gain of rainbow trout over a 12 weet: periog - Trial \#2.

sourte of 55 pre Falue de.050.01

$(t) \pi s=10)$

toted $\quad 14 x-99 \div 4$

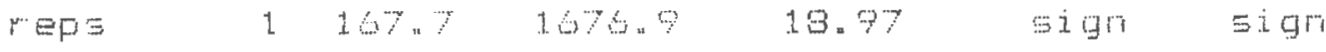

feeds 21.21. 2 5606.3 29.77 5ign sign

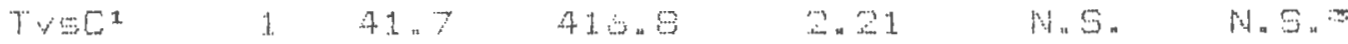

inter --

action 203.5 0.6. $117^{2} \%$ N.S. N.S.

error $\quad 1.78500 \quad 183.5$

Analyaic of yariance for actul length gan of

rainbow trotit aver a 9 weEk period - Trial \#2

\begin{tabular}{|c|c|c|c|c|c|c|}
\hline 5QL!r= & $d t$ & 55 & $M S$ & $F \quad \forall \Rightarrow I u \in$ & @ 0.05 & 0.01 \\
\hline total & 143 & 71.09 & & & & \\
\hline reps & 1 & 1.56 & 1.56 & 4.08 & $\equiv$ ign & $5 \mathrm{ign}$ \\
\hline feeds & 2 & 15.21 & 7.61 & 17.96 & sign & sign \\
\hline TVsC* & 1 & 0.47 & 0.47 & 1.22 & $N .5$. & N. \\
\hline $\begin{array}{l}\text { inter- } \\
\text { action }\end{array}$ & 2 & 1.58 & 0.89 & 1.80 & $M=\Xi$ & N.S. \\
\hline error & 1.37 & 52.4 & 0.38 & & & \\
\hline
\end{tabular}

$1=$ treatnent ven control = treatment effect

z = interetion effect of two thent and feeds (edditive)

$=\Rightarrow$ M. $S_{\mu}=$ not $\equiv$ i.gificat 
Arialysis of variance for relative gain of rainbow trout over a 12 weel period - Trial

\begin{tabular}{|c|c|c|c|c|c|c|}
\hline 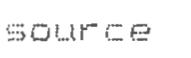 & $d f$ & .9 & $M S$ & Fvelue & 90.05 & 00.01 \\
\hline watal. & $1.4: 5$ & 12.9 & & & & \\
\hline reps & 1 & 6.78 & 6.78 & $5 L=1$ & $=19 n$ & $519 n$ \\
\hline feeds & 2 & 5.64 & 1. 320 & 118.9 & sign & S. \\
\hline$T \vee C^{x}$ & 1 & 0,11 & 0.111 & 7.90 & $=\mathrm{L}$ & sign \\
\hline $\begin{array}{l}i n \operatorname{tar} \\
\operatorname{action}=\end{array}$ & 2 & 0.22 & 0,10 & 7.0 & $=i g n$ & $=\mathrm{ict}$ \\
\hline Eror & 177 & 2.12 & $0.01 \%$ & & & \\
\hline
\end{tabular}

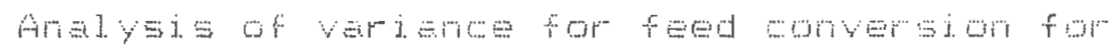

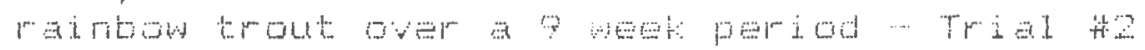

\begin{tabular}{|c|c|c|c|c|c|c|}
\hline source & $d F$ & 98 & 119 & Fylue & 0.05 & 0.01 \\
\hline total & 1. 1 & $0 . \square$ & & & & \\
\hline rEps & 1 & 0.00 & 0.077 & $12 \times 14$ & $5 \mathrm{ign}$ & $N .5 .=$ \\
\hline fЕきd & 2 & 0.24 & 0.121 & 19.17 & sign & $s i g r i$ \\
\hline$T \vee \subseteq C *$ & 1 & 0.01 & 0.011 & 1.71 & $M .5 n$ & $N, \theta^{\circ}$ \\
\hline $\begin{array}{l}\text { inter - } \\
\text { action }\end{array}$ & 2 & 0.01 & ओ. & 0.99 & N.5. & 4.9. \\
\hline Errar & 4 & $0.0 \mathrm{I}$ & 0.00 & & & \\
\hline
\end{tabular}

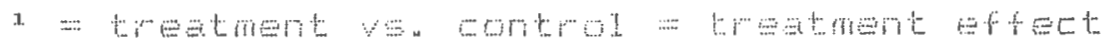

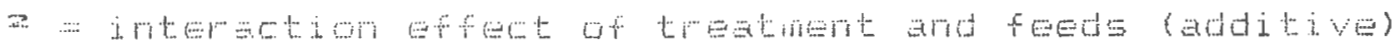

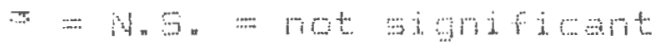


Analysis of vamiance for plasma glucose levels of

rainbow trout at termination of experiment - Trial \#2.

\begin{tabular}{|c|c|c|c|c|c|c|}
\hline sour'ce & $d f$ & 85 & 119 & F value & 0.05 & 00.01 \\
\hline & & $\begin{array}{l}\text { times) } \\
(1010)\end{array}$ & & & & \\
\hline tot: 1 & 143 & 1506 & & & & \\
\hline reps & 1 & 21.5 & 2126.9 & 5.30 & $5 i g n$ & N. S. \\
\hline fEEds & 2 & $30 \div$ & 19176.0 & 27.77 & sign & sign \\
\hline Trse' & 1 & 7.50 & 780.1 & 1.18 & H. 5. & 4.5. \\
\hline $\begin{array}{l}\text { inter- } \\
\text { action? }\end{array}$ & 2 & 10.9 & 547.7 & 0.85 & N. 5. & $N_{4} S_{n}$ \\
\hline error & 1.57 & $B 9$ & 644.2 & & & \\
\hline
\end{tabular}

Analysis of vertance for viseral fat level (\%) in rainbow trout after a 9 weet: feeding trial - Trial \#2

\begin{tabular}{|c|c|c|c|c|c|c|}
\hline source & $d f$ & $s s$ & $M S$ & F value & 0.05 & 0.01 \\
\hline total & 143 & 21.26 & & & & \\
\hline$r \in \beta \equiv$ & 1 & 0.09 & 0,095 & 0.57 & $H . S$. & N. $\mathrm{G}$. \\
\hline feeds & 2 & 0.68 & 0.54 & 2.41 & $\mathrm{H}=5$. & $N . S_{n}$ \\
\hline TVSC* & 11 & 0.002 & 0.002 & $-\cdots-$ & m. 9. & N. .5. \\
\hline $\begin{array}{l}\text { inter- } \\
\text { action }\end{array}$ & 2 & 1.11. & 0.20 & 1.47 & $H_{4}$. & 对. 3 . \\
\hline error & 137 & $17_{n} 3$ & 0.14 & & & \\
\hline
\end{tabular}

\footnotetext{
J = treatment vs. control = treatment arfect

$x=$ interaction effert of treatinent gnd feeds iadditives

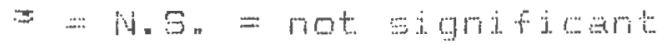


Analysis of variance for condition factior of rainbow trout fed three diets for 9 weets -.. Trial \#2.

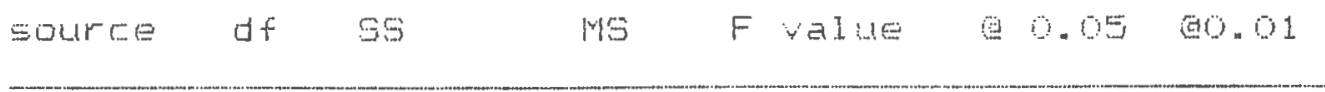

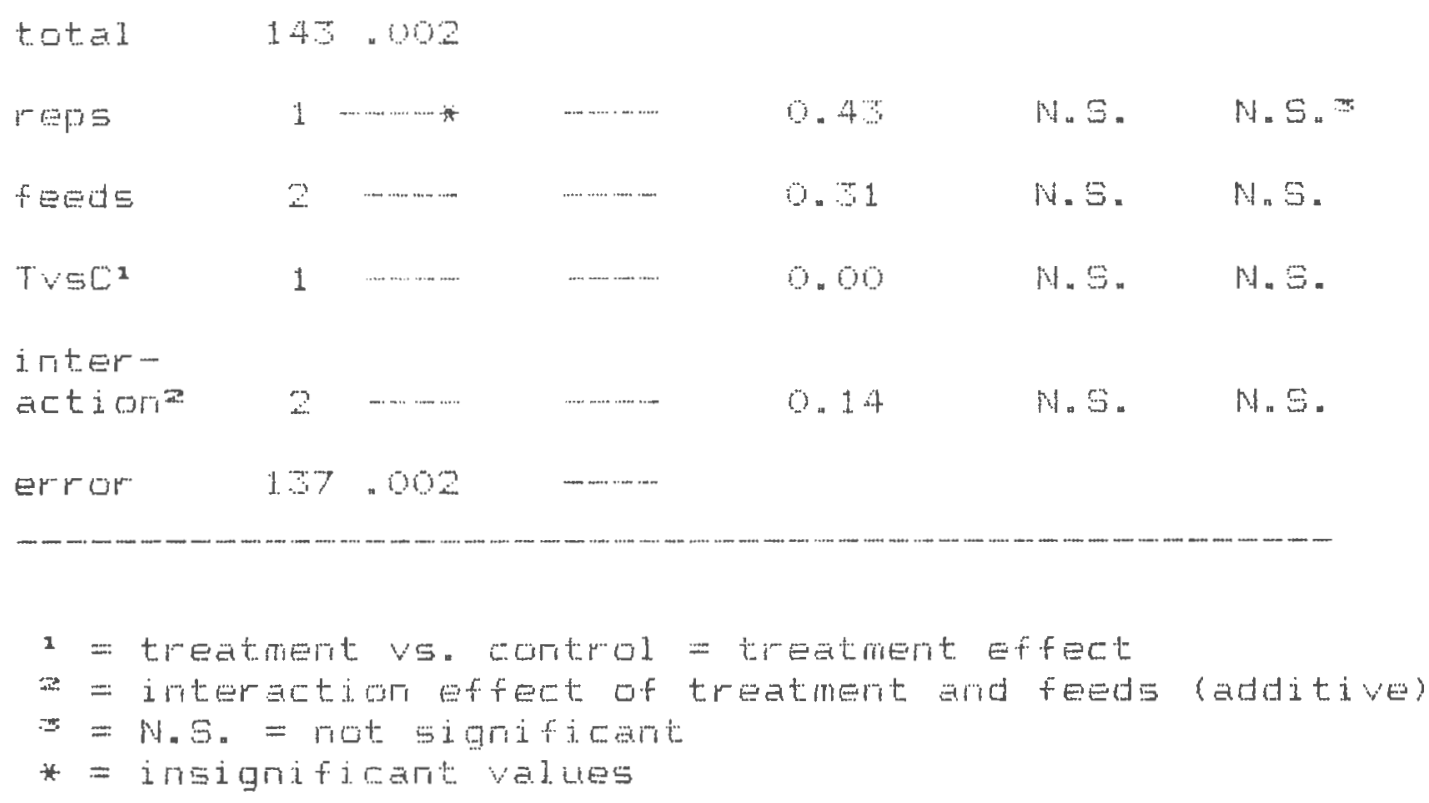

